Please do not remove this page

RMIT

UNIVERSITY

\title{
Detection of s-Triazine pesticides in natural waters by modified large-volume direct injection HPLC
}

Beale, David; Kaserzon, Sarit; Porter, Nichola; Roddick, Felicity; Carpenter, Peter

https://researchrepository.rmit.edu.au/esploro/outputs/9921858206701341/filesAndLinks?institution=61RMIT_INST\&index=null

Beale, D., Kaserzon, S., Porter, N., Roddick, F., \& Carpenter, P. (2010). Detection of s-Triazine pesticides in natural waters by modified large-volume direct injection HPLC. Talanta, 82(2), 668-674.

https://doi.org/10.1016/j.talanta.2010.05.030

Published Version: https://doi.org/10.1016/j.talanta.2010.05.030

Repository homepage: https://researchrepository.rmit.edu.au

(C) 2010 Elsevier B.V. All rights reserved

Downloaded On 2023/04/26 22:50:48 +1000

Please do not remove this page 

pesticides in natural waters by modified large-volume direct injection HPLC', Talanta, vol. 82, no. 2, pp. 668-674.

\title{
Detection of s-Triazine Pesticides in Natural Waters by
}

\section{Modified Large-Volume Direct Injection HPLC}

\author{
David J. Beale ${ }^{1 \& 3 \dagger}$, Sarit L. Kaserzon ${ }^{1}$, Nichola A. Porter ${ }^{1 \& 3^{*}}$, Felicity A. \\ Roddick $^{2} \& 3$ and Peter Carpenter ${ }^{1}$ \\ ${ }^{1}$ School of Applied Sciences, RMIT University, GPO Box 2476, Melbourne 3001, Australia. \\ ${ }^{2}$ School of Civil, Chemical and Environmental Engineering, RMIT University, GPO Box 2476, \\ Melbourne 3001, Australia. \\ ${ }^{3}$ Water Quality Research Australia (formally the CRC for Water Quality and Treatment), Private Mail \\ Bag 3, Salisbury, South Australia 5108, Australia.
}

Abstract: There is a need for simple and inexpensive methods to quantify potentially harmful persistent pesticides often found in our water-ways and water distribution systems. This paper presents a simple, relatively inexpensive method for the detection of a group of commonly used pesticides (atrazine, simazine and hexazinone) in natural waters using large volume direct injection high performance liquid chromatography (HPLC) utilizing a monolithic column and a single wavelength ultraviolet-visible light (UV-vis) detector. The best results for this system were obtained with a mobile phase made up of acetonitrile and water in a 30:70 ratio, a flow rate of $2.0 \mathrm{~mL} \mathrm{~min}^{-1}$, and a detector wavelength of $230 \mathrm{~nm}$. Using this method, we achieved retention times of less than three minutes, and detection limits of 5.7 $\mu \mathrm{g}$

Deleted: 5

\footnotetext{
${ }^{\dagger}$ Present address: CSIRO Land and Water, PO Box 56, Highett 3190, Australia.

* Corresponding author at: School of Applied Sciences (Applied Chemistry), RMIT

| University, GPO Box 2476, Melbourne 3001, Australia.

Tel.: +61 39925 1787; fax: +61 396391321 .

E-mail address: nichola.porter@rmit.edu.au (Nichola A. Porter).
}

Deleted: V

Formatted: Right: $18 \mathrm{pt}$ 
$\mathrm{L}^{-1}$ for atrazine, $4.7 \mu \mathrm{g} \mathrm{L} \mathrm{L}^{-1}$ for simazine and $4.0 \mu \mathrm{g} \mathrm{L} \mathrm{L}^{-1}$ for hexazinone. The

performance of this method was validated with an inter-laboratory trial against a

National Association of Testing Authorities (NATA) accredited liquid

chromatography - mass spectrometry/mass spectrometry (LC-MS/MS) method

commonly used in commercial laboratories.

Keywords: Atrazine, Direct injection HPLC, Hexazinone, Natural organic matter,

Natural waters, and Simazine.

\section{Introduction}

It is common practice for water utilities to apply a risk approach to pesticide residue monitoring in drinking water catchments, where pesticides are identified and the risk of contamination is calculated (i.e., solubility and mobility of pesticide being applied in conjunction with the proximity and rate of application) [1]. This information is used to inform the water utility's monitoring programme. Current Australian drinking water guidelines do not enforce a sampling program frequency (although it is recommended to sample for pesticide residues monthly), nor do they specify which pesticides are to be monitored, as no single method of analysis is suitable for all the organic compounds that may be present in water. Each compound, or perhaps group of compounds, has specific analytical requirements, so monitoring for all of them would be extremely costly, time consuming, and probably unjustified [2]. To highlight the deficiencies in current monitoring programs, Benotti et al. investigated pharmaceutical and endocrine disrupting compounds (including atrazine) in drinking water from the USA [3]. Their study concluded that the level of tertiary treatment currently applied by 19 water utilities resulted in atrazine and other potentially $\underline{\text { harmful chemicals passing through to finished drinking water, and in some instances }}$
Formatted: Line spacing: Double, Don't adjust space between Latin and Asian text

Deleted: Pesticides are an integral part of modern agriculture. It is estimated that at the beginning of the $21^{\text {st }}$ century pesticide use worldwide exceeded US\$8 billion per annum, while herbicides accounted for $37 \%$ of total use $[1,2]$. Two classes of herbicides that have received a great deal of attention in recent times are the quaternary ammonium heterocyclic s-

triazines and the triazinone based pesticides. Triazine and triazinone herbicides represent widely used selective pesticides characterized by three heterocyclic nitrogen atoms in ring structures. They are generally used to control broadleaf and grassy weeds in agricultural areas, plantations, and in public and industrial landscapes [3]. The most commonly used striazines are atrazine, simazine, cyanazine, prometon and propazine; metribuzin and hexazinone are commonly used triazinone pesticides.

These pesticides are relatively stable in water, extremely persistent and have been detected in ground and surface waters in Australia, the UK and the US with residual levels exceeding the World Health Organization guidelines [4-7]. ๆ

Continued application of these herbicides within Australia has prompted community concern as expressed in national newspaper reports by Dayton and Denholm [8] who reported an increase in observed health effects arising from pesticide over-spraying in surrounding communities in Tasmania, Australia. Denholm [9], noted simazine in Australian swimming pools at levels above the Australian allowable daily intake limit of $20 \mu \mathrm{g} \mathrm{L}^{-1}$ [10]. Similarly, Cornish [11] reported runoff of an estimated 1.5 tonnes of atrazine from farmland into surrounding oceans near the Great Barrier Reef by floodwaters (after Lewis et al. [12]). ๆ

It is common practice for water utilities to apply a risk approach to pesticide residue monitoring in drinking water catchments, where pesticides are identified and the risk of contamination is calculated (i.e., solubility and mobility of pesticide being applied in

Formatted: Line spacing: Double

Formatted: Right: $18 \mathrm{pt}$ 
at concentrations as high as $0.9 \mu \mathrm{g} \mathrm{L}^{-1}$ (note current US EPA drinking water

guidelines for atrazine are set at $\left.3 \mu \mathrm{g} \mathrm{L}^{-1}[4]\right)$. Of greater concern was the presence of atrazine in waters in areas where this compound was not believed to be in use [3].

While current standard methods recommended for the determination of pesticide

residues are satisfactory with respect to detection limits and analytical performance,

they are often criticized for the time and costs involved. The development of new cost

effective and rapid methodologies is becoming increasingly desirable because they

enable water utilities to increase the frequency of sampling and broaden the range of

pesticides analysed, giving them a better picture of the state of contamination in their

system. As such, many researchers are looking for new techniques that address this

time and cost problem, and to achieve this, some are considering enhancement and

further development of liquid chromatographic techniques, in particular HPLC, UPLC

and LC as shown in Table 1.

Table 1: Summary of recent developments in rapid pesticide analysis by HPLC

\begin{tabular}{|c|c|c|c|c|c|c|}
\hline Method & Analyte & $\frac{\text { Separation }}{\text { Column }}$ & $\frac{\text { Extraction }}{\text { type }}$ & $\begin{array}{l}\frac{\text { Retention }}{\text { time }\left(T_{R}\right)} \\
\text { (minutes) }\end{array}$ & $\frac{\frac{\text { Limit of }}{\text { Detection }}}{\underline{(\text { LOD })}}$ & $\underline{\text { Reference }}$ \\
\hline \multirow[t]{2}{*}{ HPLC UV } & Atrazine & RP-C18 & SPE & 34 & $=$ & [5] \\
\hline & $\begin{array}{l}\text { Simazine } \\
\frac{33 \text { pesticides }}{\text { analysed in } 90} \\
\underline{\text { minutes })}\end{array}$ & & & $\underline{23}$ & & \\
\hline \multirow[t]{2}{*}{ HPLC-UV } & Atrazine & $\underline{\mathrm{RP}-\mathrm{C} 18}$ & Liquid & 10 & $\underline{0.1}$ & {$[6,7]$} \\
\hline & $\underline{\text { Simazine }}$ & & & $\underline{12.6}$ & $\underline{0.04}$ & \\
\hline \multirow[t]{2}{*}{ LC-ES-MS } & Atrazine & ACQUITY & SPE & $\underline{2.37}$ & $\underline{0.0006}$ & [8] \\
\hline & $\underline{\text { Simazine }}$ & BEH C18 & & $\underline{1.91}$ & $\underline{0.00008}$ & \\
\hline \multirow{2}{*}{$\frac{\text { UPLC-ESI- }}{\underline{\mathrm{MS} / \mathrm{MS}}}$} & Atrazine & BEH C18 & SPE & $\underline{2.3}$ & $\underline{0.006}$ & [9] \\
\hline & $\underline{\text { Simazine }}$ & $\underline{\text { column }}$ & & $\underline{1.6}$ & $\underline{0.01}$ & \\
\hline HPLC-UV & Hexazinone & RP-C18 & Direct injection & $\underline{7.9}$ & $\underline{0.3}$ & [10] \\
\hline \multirow[t]{2}{*}{ LC-EIS-MS } & Atrazine & XDB-C18 & Direct injection & 4.39 & $\underline{0.3}$ & [11] \\
\hline & Simazine & & & $\underline{4.36}$ & & \\
\hline
\end{tabular}

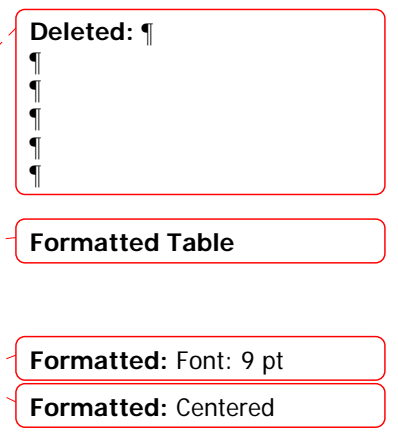

\begin{tabular}{|l|}
\hline Formatted: Font: $9 \mathrm{pt}$ \\
\hline Formatted: Centered \\
\hline Formatted: Font: $9 \mathrm{pt}$ \\
\hline Formatted: Centered \\
\hline Formatted: Centered \\
\hline Formatted: Font: $9 \mathrm{pt}$ \\
\hline Formatted: Font: $9 \mathrm{pt}$ \\
\hline Formatted: Font: $9 \mathrm{pt}$ \\
Formatted: Centered \\
Formatted: Right: $18 \mathrm{pt}$ \\
\hline
\end{tabular}


Although LC-MS methods offer significant reductions in detection limits, and considerable effort has been expended to reduce retention times by employing fast short narrow bore columns and high mobile flow rates operating under increased pressure (i.e., retention times commonly achieved between ca. 2 to 5 minutes for atrazine and simazine $[8,9,11])$. Shortening the analytical run time is an important step towards high sample throughput often required in commercial laboratories conducting routine pesticide monitoring. Run times of several tens of minutes is not acceptable and emphasis has been directed towards ensuring maximum chromatographic resolution in a significantly reduced time. However, LC-MS methods are still considered to be highly sophisticated and expensive pieces of equipment requiring specialized personnel to operate and interpret MS data [12]. In contrast, conventional HPLC-UV methods are typically more robust, cheaper and easier to operate ${ }_{2}$ but fall short in terms of required detection limits and the time required for analysis. Recent advancements in monolithic column technology have lead to an improvement in peak resolution and combined with HPLC, provide an affordable option for fast screening of samples prior to confirmation by LC-MS if required. In general, resolution between solute bands depends on the square root of column efficiency (i.e., the number of theoretical plates (NTP)), which in turn is proportional to the reciprocal of particle diameter $\left(1 / \mathrm{d}_{\mathrm{p}}\right)$ of the column packing material. Concurrently the pressure drop across the column is inversely proportional to the square of $d_{p}$. Attempts to obtain greater NTP by decreasing particles size, results in significant increases in instrument operational pressure often exceeding the instrument specifications. The structure of monolithic columns overcomes this problem $[13]$

Deleted: which

Deleted: exceeds

Deleted: 24 
Monolithic columns are prepared by in-situ polymerization of monomers in a column,

providing greater flexibility than densely packed columns, and a wider range of

monomers can be used with integrated structures that can increase the overall

porosity. The higher porosity leads to an increase in permeability which consequently

results in a decrease in the required operational pressure. Coupled with the presence

of small-sized mono structure skeleton, higher efficiencies can be expected. Up to

now, monolithic columns have been used mainly for the determination of biological

amino acids and drug residues [14], although there have been some instances of

monolithic chromatography for pesticide analysis (see Table 2); However, its

application to natural waters without pre treatment is limited [15].

Formatted: Highlight

\begin{tabular}{|l|}
\hline Deleted: 25 \\
\hline Formatted: Not Highlight \\
\hline Deleted: modified \\
\hline $\begin{array}{l}\text { Deleted: flow injection and } \\
\text { sequential injection techniques }\end{array}$ \\
\hline $\begin{array}{l}\text { Deleted: e.g. Chocholouš et } \\
\text { al.)[26]. }\end{array}$ \\
\hline Formatted: Not Highlight \\
\hline Formatted: Not Highlight \\
\hline
\end{tabular}


Table 2: Summary of chromatography monolithic separation methods for pesticide analysis.

\begin{tabular}{|c|c|c|c|c|c|c|}
\hline \multirow[t]{2}{*}{ Method } & \multirow[t]{2}{*}{ Analyte } & \multirow[t]{2}{*}{$\frac{\text { Sample }}{\text { matrix }}$} & $\frac{\text { Extraction }}{\text { type }}$ & $\frac{\text { Retention }}{\text { time }\left(T_{R}\right)}$ & $\frac{\text { Limit of }}{\text { Detection }}$ & Reference \\
\hline & & & & (minutes) & $\left(\mu \mathrm{gL}^{-1}\right)$ & \\
\hline HPLC-UV & Fenoxycarb & Veterinary & $\underline{S P E}$ & 1.8 & 2000 & [16] \\
\hline & Permethrin & sprays & & 7.2 & 1000 & \\
\hline HPLC-MS/MS & Atrazine & Natural & SPE & Ca. 2.0 & 0.002 & 171 \\
\hline & Simazine & waters, & & $\mathrm{Ca} .1 .5$ & 0.001 & \\
\hline & $\frac{\frac{\text { (plus } 9}{\text { additional }}}{\text { pesticides) }}$ & & & & & \\
\hline$\underline{C E C}$ & $\frac{17 \text { different }}{\text { pesticides and }}$ & millio & is & $\leq 2.1$ & $\overline{\text { in }}$ & [18] \\
\hline
\end{tabular}

While monolithic columns have been used previously for the determination of

pesticides; the application has involved specialised expensive equipment (e.g. HPLC-

MS/MS) or has been applied to sample matrices comprising concentrated

formulations $\sqrt{ }[16,17]$. Similarly, more conventional methods (utilising packed

columns) have relied on specific extraction techniques, increased operating pressures

and sophisticated detectors to remove interferences, concentrate target analytes and

decrease detection limits. The purpose of this research is to devise a simple,

affordable, robust HPLC method utilising a monolithic column and UV-vis detection

for the determination of pesticides in natural waters without any pre-treatment (e.g.

sample extraction). As such, this paper describes the development of a rapid, cost

effective, large volume direct injection HPLC method utilizing a monolithic column

with UV detection for the combined determination of atrazine, simazine and

hexazinone in natural waters. The development of the proposed method is described

and compared to a conventional packed column. The method is applied to natural

water samples and cross validated against a commercially operated, NATA
Deleted: q

This

Formatted: Not Highlight

\begin{tabular}{|c|c|}
\hline Formatted & $\ldots[2]$ \\
\hline Formatted & $\ldots[3]$ \\
\hline Formatted & $\ldots[4]$ \\
\hline Formatted & $\ldots[5]$ \\
\hline Formatted & $\ldots[6]$ \\
\hline Formatted & $\ldots[7]$ \\
\hline \multicolumn{2}{|c|}{ Formatted: Not Highlight } \\
\hline Formatted & $\ldots[8]$ \\
\hline Formatted & $\ldots[9]$ \\
\hline Formatted & $\ldots[10]$ \\
\hline Formatted & $\ldots[11]$ \\
\hline Formatted & $\ldots[12]$ \\
\hline Formatted & $\ldots[13]$ \\
\hline Formatted & $\ldots[14]$ \\
\hline Formatted & $\ldots[15]$ \\
\hline Formatted & $\ldots[16]$ \\
\hline \multicolumn{2}{|c|}{ Comment [N1]: Are t ... [17] } \\
\hline \multicolumn{2}{|c|}{ Comment [DB2]: Yes ... [18] } \\
\hline Formatted & $\ldots[19]$ \\
\hline Formatted & $\ldots[20]$ \\
\hline Formatted & $\ldots[21]$ \\
\hline Formatted & $\ldots[22]$ \\
\hline Formatted & $\ldots[23]$ \\
\hline Formatted & $\ldots[24]$ \\
\hline Formatted & $\ldots[25]$ \\
\hline Formatted & $\ldots[26]$ \\
\hline Formatted & $\ldots[27]$ \\
\hline Formatted & $\ldots[28]$ \\
\hline Formatted & $\ldots[29]$ \\
\hline Formatted & $\ldots[30]$ \\
\hline Formatted & $\ldots[31]$ \\
\hline Formatted & $\ldots[32]$ \\
\hline Formatted & $\ldots$ [33] \\
\hline Formatted & $\ldots[34]$ \\
\hline Formatted & $\ldots[35]$ \\
\hline Formatted & $\ldots[36]$ \\
\hline Formatted & $\ldots$ [37] \\
\hline Formatted & $\ldots[38]$ \\
\hline Formatted & $\ldots$ [39] \\
\hline Formatted & $\ldots[40]$ \\
\hline Formatted & $\ldots[41]$ \\
\hline Formatted & $\ldots[42]$ \\
\hline Formatted: & \\
\hline
\end{tabular}


accredited, MS method (conducted by SGS Consulting, Australia). An investigation into possible interferences is also presented.

\section{Materials and methods}

\section{Solution preparation}

A stock solution of atrazine $\left(9.8 \mathrm{~g} \mathrm{~L}^{-1}\right.$; Supelco, Germany. Neat analytical standard Formatted: Line spacing:

(NAS)), was prepared in $10 \mathrm{~mL}$ acetonitrile and sonicated for an hour. Similar stock solutions of simazine $\left(10.0 \mathrm{~g} \mathrm{~L}^{-1}\right.$; Supelco, USA. NAS $)$ and hexazinone $\left(10.0 \mathrm{~g} \mathrm{~L}^{-1}\right.$; Supelco, USA. NAS) were also prepared. Working standard solutions of atrazine, simazine and hexazinone were prepared daily in MilliQ water. Stock solutions were stored at $4{ }^{\circ} \mathrm{C}$ in the dark when not in use.

\section{Dissolved organic carbon (DOC)}

After filtration using $0.45 \mu \mathrm{m}$ hydrophilic membrane (Durapore PVDF) dissolved organic carbon (DOC) in water samples was determined in triplicate using a Sievers 820 TOC analyser.

\section{Direct injection HPLC}

HPLC with direct injection was carried out with a Waters HPLC pump (M-6000A,

Waters Associates Inc., USA.) operated isocratically. $500 \mu \mathrm{L}$ Aqueous samples were injected via a Waters HPLC injection valve fitted with a $500 \mu \mathrm{L}$ loop using a $2 \mathrm{~mL}$ glass barrel syringe. The injected sample was passed through a monolithic column RP-18e, 50-4.6 mm (by Chromolith, Merck); for comparison a secondary column was used, a C8, $5 \mu \mathrm{m}, 250 \mathrm{~mm} \times 4.6 \mathrm{~mm}$ (model 831815 Spherisorb, Phase Separations, 
nm, coupled to a chart recorder (Model 3395, Hewlett Packard, USA) and a personal computer operating ChemStation (Agilent, USA). Where noted, chromatograms were digitised from paper chromatograms and reproduced using GraphClick software (Mac

\section{OS X, Arizona Software, Switzerland).}

\section{Solid phase extraction (SPE)}

SPE cartridges $(0.5 \mathrm{mg}$ Bond Elute C18) were pre-conditioned with $5 \mathrm{~mL}$ methanol followed by $5 \mathrm{~mL}$ MilliQ water (Millipore MilliQ Water System) prior to sample introduction ( $1 \mathrm{~L}$ aliquot, filtered via $0.45 \mu \mathrm{m}$ hydrophilic membrane) at $2-4 \mathrm{~mL}$ $\min ^{-1}$ using a 12 port vacuum SPE manifold (Varian, Australia) and Visiprep SPE tubing (Varian, Australia). The SPE cartridges were then air dried under a vacuum and eluted using $4 \mathrm{~mL}$ of 90:10 methyl-tert-butyl-ether : ethyl acetate. Samples were then evaporated to dryness under nitrogen and reconstituted in 40:60 (v:v)

$\mathrm{MeOH}: \mathrm{H}_{2} \mathrm{O}$, to final eluent volume of $5.0 \mathrm{~mL}$.

\section{LC-MS}

LC - MS/MS analysis was carried out at SGS Australia Pty Ltd. Instrumentation comprised an LC (Agilent 1200 Series) with a Waters Atlantis T3 column and a MS/MS system (Applied Biosystems API 3200). A mixed $100 \mu \mathrm{L}$ sample volume was injected into the LC using an auto-sampler. Samples were analysed without preconcentration using a buffered mobile phase $\left(\mathrm{MeOH}: \mathrm{H}_{2} \mathrm{O}\right)$. Quantification ions used were $216 / 174 \mathrm{mz}$ for atrazine, $202.1 / 132.1 \mathrm{mz}$ for simazine, $253.2 / 171.2 \mathrm{mz}$ for hexazinone. The full method can not be entirely disclosed due to intellectual confidentiality but it is NATA accredited and follows ISO 9001 QC protocols (SGS 2009).
Formatted: Font: $12 \mathrm{pt}$

Formatted: Font: $12 \mathrm{pt}$

Formatted: Font: $12 \mathrm{pt}$

Formatted: Font: $12 \mathrm{pt}$

Formatted: Font: $12 \mathrm{pt}$

Formatted: Font: $12 \mathrm{pt}$

Comment [N4]: Should be in methods

Mmm maybe, but I think it is

okay here, it relates only to this graph... have made an addition in the methods

Formatted: Default Paragraph Font, English (Australia)

Formatted: Font: 12 pt, Font color: Auto

Formatted: Line spacing: Double, Don't adjust space between Latin and Asian text

Formatted: Line spacing:

Double

Formatted: Line spacing: Double, Don't adjust space between Latin and Asian text

Formatted: Line spacing: Double 


\section{Statistical methodology}

The analytical performance was assessed by determining the limit of detection (LOD),

limit of quantification (LOQ) and practical method detection limit (MDL), where

LOD was calculated using a signal to noise ratio $(\mathrm{S} / \mathrm{N})$ of $3, \mathrm{LOQ}$ was calculated using $\mathrm{S} / \mathrm{N}$ of 10 , and the MDL was calculated using the lowest standard $(\mathrm{n}=8)$, where the SD was calculated and multiplied by the student $\mathrm{t}-\mathrm{value}$ at a $95 \%$ confidence level

\section{[19].}

\section{Results and Discussion}

\section{Mobile phase optimisation}

A mobile phase method development triangle was created according to Harris $[19]$.

Method development triangles are a systematic process applied in HPLC to develop a mobile phase suitable for the separation of the target analytes using a combination of solvents: in this case $\mathrm{MeOH} ; \mathrm{ACN}$, acetonitrile; and $\mathrm{H}_{2} \mathrm{O}$, MilliQ water. Solvents were varied from 10 to $90 \% \mathrm{v}: \mathrm{v}: \mathrm{v}$ at intervals of $10,30,50,70$, and $90 \%$ for combinations consisting of two solvents; and at 10, 15, 25, 33.3, 85, 75, $67.7 \%$ intervals for mobile phases comprising three solvents until the best separation was achieved. While combinations of $\mathrm{MeOH}, \mathrm{ACN}$ and water mobile phases were all effective for analysing the individual triazine compounds, hexazinone and simazine co-eluted when all three compounds were present; however ${ }_{2}$ this was overcome utilising a 30:70 (v:v) $\mathrm{ACN}: \mathrm{H}_{2} \mathrm{O}$ mobile phase. It is important to note the HPLC column was maintained under stable standard laboratory conditions $\left(\mathrm{Ca}^{2}{ }^{\circ} 2^{\circ} \mathrm{C}\right)$ and all working solutions were brought to room temperature prior to analysis. Since it was the intention to develop a cheap robust HPLC method a column heater (e.g. a thermostatically controlled column) was not implemented.

Formatted: Font: $12 \mathrm{pt}$, Not Highlight

Deleted: $\mathrm{x}$ standard deviation (SD) of the baseline $(n=4)$

Formatted: Font: 12 pt, Not Highlight

Deleted: $x \mathrm{SD}$ of the baseline $(\mathrm{n}=4)$

Deleted: one sided paired

Formatted: Font: 12 pt, Not Highlight

Deleted: distribution

Formatted: Font: 12 pt, Not Highlight

Deleted:

Comment [N5]: Add reference

Formatted: Line spacing: Double, Don't adjust space between Latin and Asian text

Deleted: [27

Formatted: Line spacing:

Double

Deleted: ;

Deleted: of

Formatted: Font: 12 pt, Not Highlight

Comment [DB6]: It is approximately $22 \mathrm{C}$... without the ca. it comes across as a finite temp which it isnt

Formatted: Font: 12 pt, Italic, Not Highlight

Formatted: Font: $12 \mathrm{pt}$, Not Highlight

Formatted: Font: 12 pt, Not Highlight

Formatted: Right: $18 \mathrm{pt}$ 


\section{Effect of mobile phase flow rate}

The effect of the mobile phase flow rate on the direct injection HPLC analysis of

atrazine, hexazinone and simazine was investigated over $0.25-3.00 \mathrm{~mL} \mathrm{~min}^{-1}$ in 0.25

$\mathrm{mL} \min ^{-1}$ increments. However, the mobile phase flow rate when using the monolithic

Deleted:

column did not significantly influence the instrument operating pressure or the quality of the chromatography (i.e., peak width and resolution). Consequently, a flow rate of

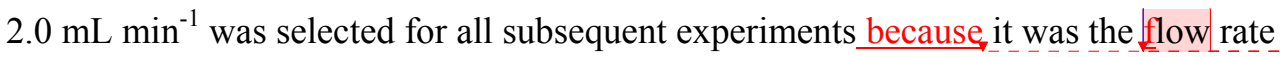
which achieved the best baseline separation between all analytes selected and was the fastest flow rate that could be used with the packed C8 column enabling a comparison between the two columns under the same conditions to be made.

\section{Effect of injection volume}

The effect of the sample injection volume on the direct injection HPLC analysis of atrazine, hexazinone and simazine was investigated over $100-1000 \mu \mathrm{L}$. It was found that the analyte peak area steadily increased as the volume increased from $100 \mu \mathrm{L}$ to $1000 \mu \mathrm{L}$; however, the best peak shape was achieved using $500 \mu \mathrm{L}$. Injection volumes larger than $500 \mu \mathrm{L}$ distorted the symmetry of the peak, causing peaks to become broader. All subsequent analysis was performed using a filled $500 \mu \mathrm{L}$ sample injection loop.

\section{Effect of detector wavelength}

A number of researchers have investigated atrazine, hexazinone or simazine at wavelengths between 220 and $223 \mathrm{~nm}$ for atrazine and simazine, as well as hexazinone at $244 \mathrm{~nm}[21,22]$. However, when applying these wavelengths for the simultaneous determination of atrazine, hexazinone and simazine (e.g., either 220-3 $\mathrm{nm}$ or $244 \mathrm{~nm}$ ) there is a decrease in analyte sensitivity for either atrazine and

Formatted: Line spacing: Double, Don't adjust space between Latin and Asian text

Formatted: Line spacing: Double

Deleted: [29, 30]. 
simazine or hexazinone (depending on the wavelength selected) unless a diode-array detector (DAD) is employed. In the absence of a DAD, the analysis has to be performed utilizing a common wavelength. As illustrated in Figure 1, the UV spectra of atrazine and simazine intersect with the spectra of hexazinone at ca. $230 \mathrm{~nm}$.

Figure 1 also shows that the influence of DOC at $230 \mathrm{~nm}$ relative to $220 \mathrm{~nm}$ potentially poses a problem if present at high concentrations and is found to co elute with the target analytes in natural water samples.

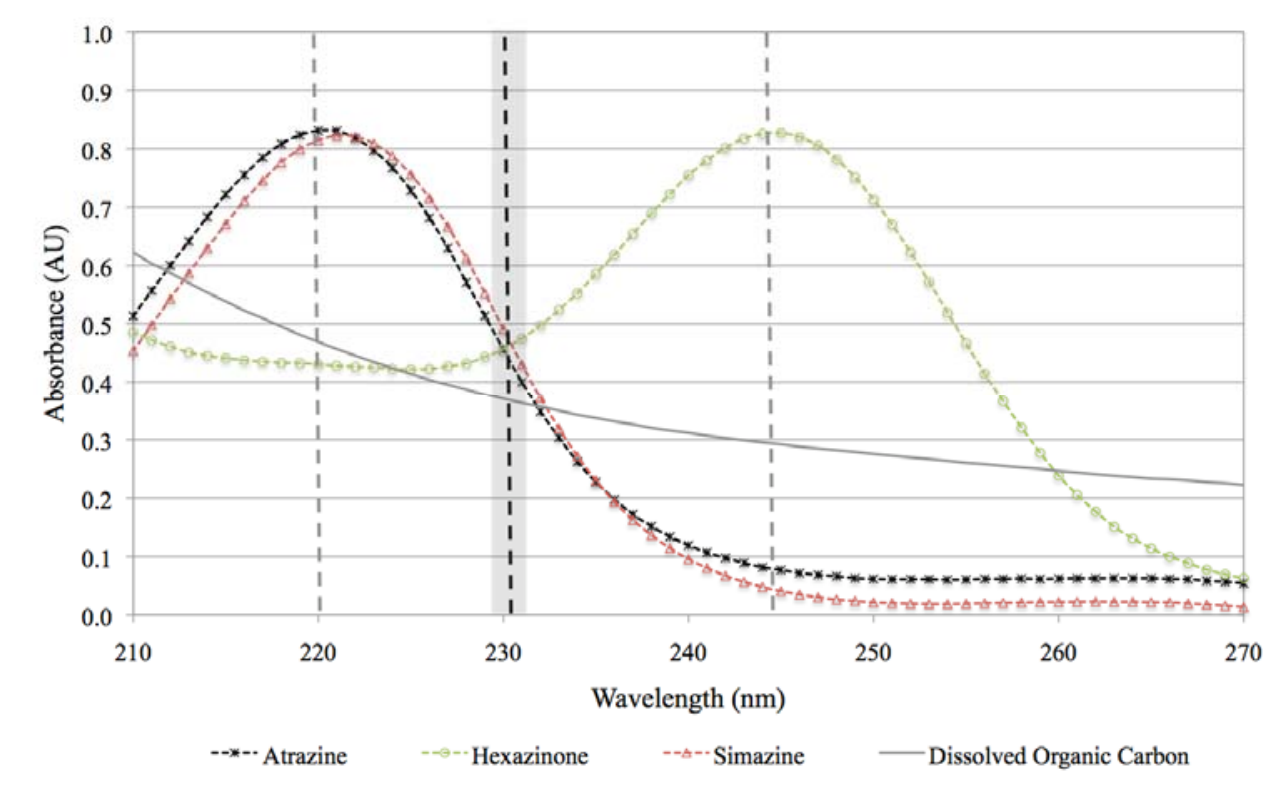

\section{Figure 1: UV spectra of atrazine, hexazinone, and simazine (500 $\left.\mathrm{g} \mathrm{L} \mathrm{L}^{-1}\right)$ in MilliQ}

$\underline{\text { water and a natural water sample containing } 11.1 \mathrm{mg} \mathrm{L}^{-1} \text { dissolved organic }}$

carbon.

\section{Limit of detection}

Pesticides at standard concentrations over the range 5-50 $\mu \mathrm{g} \mathrm{L}^{-1}$ were prepared in

MilliQ water and analysed using the best operating conditions determined: sample injection volume of $500 \mu \mathrm{L}$, mobile phase of $30: 70 \mathrm{ACN}: \mathrm{H}_{2} \mathrm{O}$ at $2 \mathrm{~mL} \mathrm{~min}^{-1}$ with detector wavelengths of 220, 230 and $244 \mathrm{~nm}$. The analytical and statistical 
parameters obtained for the determination of the three pesticides by direct injection

HPLC are summarised in Table 3. Figure 2 illustrates the difference in

Deleted: 2 .

chromatographic separation over the three different wavelengths for the monolithic column.

Deleted: The use of $230 \mathrm{~nm}$

reduced the sensitivity by $35 \%$ for atrazine compared to the

wavelength for its maximum

sensitivity $\left(\lambda_{\max }\right), 33 \%$ for

hexazinone and $34 \%$ for simazine.

Nevertheless the reduction in

sensitivity had a minimal effect on

the detection limits. Hence it is

possible to analyse a range of

triazines using a constant

wavelength with a simple mono

wavelength UV detector while

still achieving good analytical

sensitivity for all three target

analytes.

The analytical performances

between the packed and

monolithic columns are

comparable (i.e., the analytical

figures of merit (LOD) for the

monolithic column are within \pm

$0.7 \mu \mathrm{g} \mathrm{L}^{-1}$ at 220 and $244 \mathrm{~nm}$; and

$\pm 5 \mu \mathrm{g} \mathrm{L}^{-1}$ at $230 \mathrm{~nm}$ when

directly compared with the packed

column). The great advantage of

the monolithic column over the

packed column is the reduction in

retention time for each analyte,

resulting in a significantly

reduced analysis time and

operating pressure; i.e., $1.5 \mathrm{~mL}$

$\min ^{-1}$ 
Table 3- Summary of analytical figures of merit for the determination of atrazine, simazine and hexazinone in MilliQ water by direct

\section{injection HPLC}

\begin{tabular}{|c|c|c|c|c|c|c|c|c|c|}
\hline \multirow{4}{*}{ Statistical figures of merit } & \multicolumn{9}{|c|}{ UV-vis Detector Wavelength } \\
\hline & \multicolumn{4}{|c|}{$\underline{220 \mathrm{~nm}}$} & \multirow{2}{*}{\multicolumn{2}{|c|}{$\begin{array}{l}244 \mathrm{~nm} \\
\text { Hexazinone }\end{array}$}} & \multicolumn{3}{|c|}{$230 \mathrm{~nm}$} \\
\hline & \multicolumn{2}{|c|}{ Atrazine } & \multicolumn{2}{|c|}{ Simazine } & & & \multirow{2}{*}{$\frac{\text { Atrazine }}{\text { Mono. }}$} & \multirow{2}{*}{$\frac{\text { Simazine }}{\text { Mono. }^{*}}$} & \multirow{2}{*}{$\frac{\text { Hexazinon }}{\text { Mono. }^{*}}$} \\
\hline & Mono.* & Pack. $^{\dagger}$ & Mono. ${ }^{*}$ & Pack. $^{\dagger}$ & Mono. ${ }^{*}$ & Pack. $^{\dagger}$ & & & \\
\hline Slope & 6979 & 6907 & 7793 & 7459 & 8724 & $\underline{9413}$ & $\underline{519}$ & $\underline{369}$ & 172 \\
\hline Intercept & -3370 & -536 & -13483 & 3413 & $\underline{645}$ & 502 & $\underline{-1920}$ & $\underline{-825}$ & -357 \\
\hline Linear dynamic range $\left(\mu \mathrm{g} \mathrm{L}^{-1}\right)$ & $\underline{5-50}$ & 5-50 & $5-50$ & 5-50 & $\underline{1-50}$ & $\underline{0.5-50}$ & $\underline{5-50}$ & 5-50 & $\underline{5-50}$ \\
\hline $\operatorname{LOD}\left(\mu \mathrm{g} \mathrm{L}^{-1}\right)$ & 0.7 & 0.6 & 1.8 & 0.4 & 0.1 & 0.3 & 5.7 & 4.7 & 4.0 \\
\hline $\mathrm{LOQ}\left(\mu \mathrm{g} \mathrm{L}^{-1}\right)$ & 1.2 & 1.5 & 2.1 & 1.3 & $\underline{0.4}$ & 1.2 & 10.6 & 10.7 & 8.5 \\
\hline $\mathrm{MDL}\left(\mu \mathrm{gL}^{-1}\right)$ & 1.1 & 1.4 & 1.2 & 3.0 & $\underline{0.9}$ & 1.1 & 4.1 & 2.5 & 2.6 \\
\hline SD of the intercept & 4916 & $\underline{6180}$ & 14221 & $\underline{3891}$ & $\underline{524}$ & $\underline{1289}$ & $\underline{314}$ & $\underline{272}$ & $\underline{97}$ \\
\hline SD of the slope & $\underline{143}$ & $\underline{200}$ & $\underline{280}$ & $\underline{126}$ & $\underline{246}$ & $\underline{245}$ & $\underline{10}$ & $\underline{9}$ & $\underline{3}$ \\
\hline SD of the regression & $\underline{6347}$ & $\underline{9598}$ & $\underline{19389}$ & 6043 & $\underline{719}$ & $\underline{2412}$ & $\underline{361}$ & $\underline{312}$ & $\underline{111}$ \\
\hline Correlation coefficient & 0.9978 & 0.9976 & 0.9921 & 0.9991 & 0.9976 & 0.9973 & $\underline{0.9977}$ & $\underline{0.9966}$ & $\underline{0.9980}$ \\
\hline
\end{tabular}

Note: ${ }^{*}$ HPLC system with monolithic separation column (Mono), retention time(s) for 220/244 nm at flow rate $3.0 \mathrm{~mL} \mathrm{~min}^{-1}$ : atrazine $1.77 \mathrm{mins}$; simazine $1.12 \mathrm{mins}$;

hexazinone $0.98 \mathrm{mins}$; and for $230 \mathrm{~nm}$ at flow rate $2.0 \mathrm{~mL} \mathrm{~min}^{-1}$ : atrazine $2.71 \mathrm{mins}$; simazine $1.71 \mathrm{mins}$; hexazinone 1.53.

†HPLC system (Packed) described by Beale et al. [20] retention time (s) for 220/244 nm at flow rate of $2.0 \mathrm{~mL} \mathrm{~min}^{-1}$ : atrazine 6.77 mins; simazine 4.12 mins; hexazinone $\underline{3.98 \mathrm{mins}}$. 


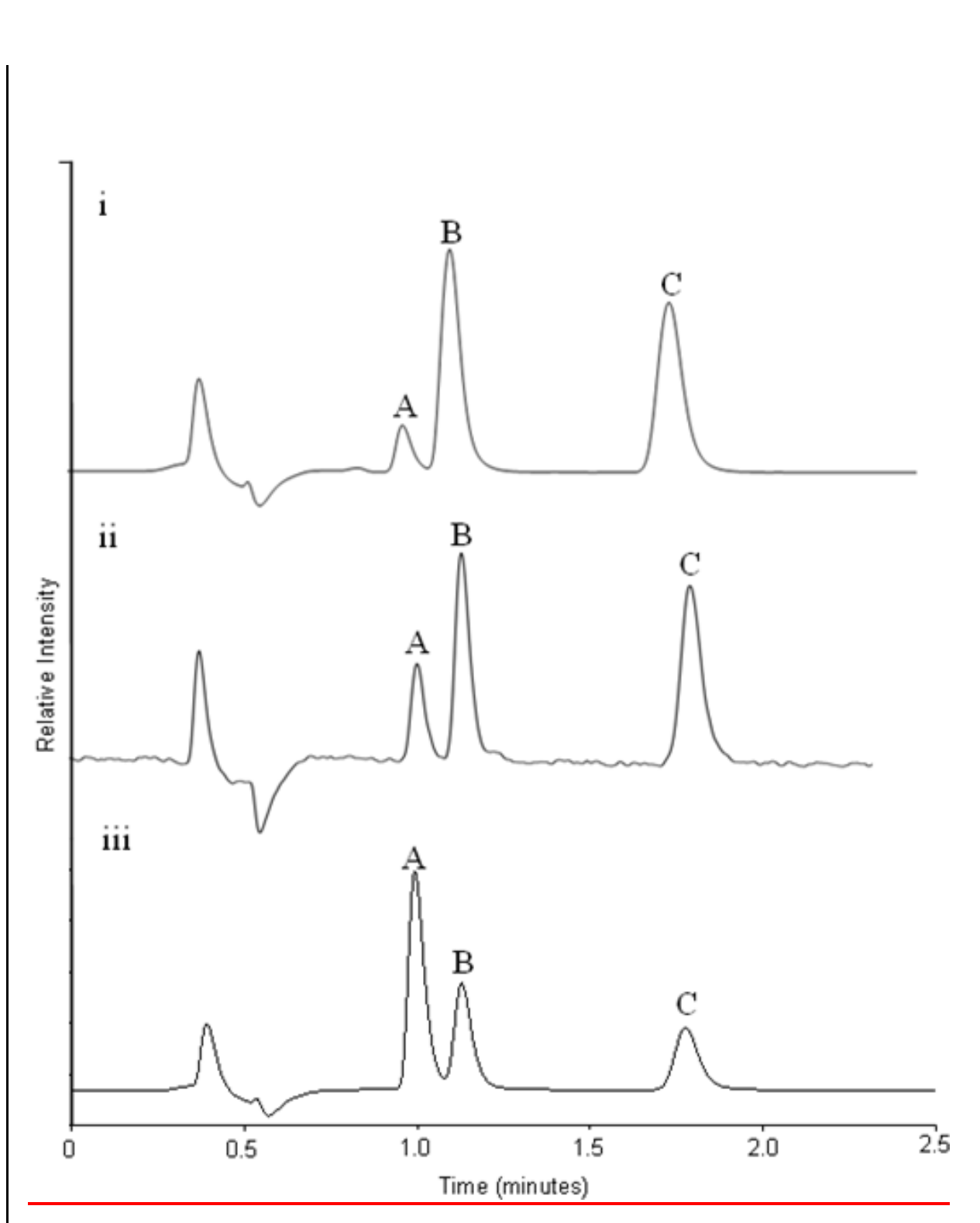

Figure 2: Monolithic column chromatograms of $50 \mu \mathrm{g} \mathrm{L} \mathrm{L}^{-1}$ stock solution of atrazine, simazine and hexazinone with UV-vis detection at 220, 230, and 244 $\underline{\mathrm{nm}}$.

NOTE: peaks identified as (A) hexazinone; (B) simazine; (C) atrazine. Sample solution consisted of 50 $\mu \mathrm{g} \mathrm{L}^{-1}$ pesticide in milliQ water, $500 \mu \mathrm{L}$ injection. Mobile phase $30: 70\left(\mathrm{ACN}: \mathrm{H}_{2} \mathrm{O}\right)$ with a UV-vis detector $(\mathrm{i}=\lambda 220 \mathrm{~nm}$; $\mathrm{ii}=\lambda 230 \mathrm{~nm}$; $\mathrm{iii}=\lambda 244 \mathrm{~nm})$, flow rate $2.0 \mathrm{~mL} \mathrm{~min}^{-1}$. 
The use of $230 \mathrm{~nm}$ reduced the sensitivity by $35 \%$ for atrazine compared to the

wavelength for its maximum sensitivity $\left(\lambda_{\max }\right), 33 \%$ for hexazinone and $34 \%$ for

simazine. Nevertheless the reduction in sensitivity had a minimal effect on the

detection limits. Hence, it is possible to analyse a range of triazines using a constant

wavelength with a simple mono wavelength UV detector while still achieving good

analytical sensitivity for all three target analytes.

The analytical performances between the packed and monolithic columns are

comparable (i.e., the analytical figures of merit (LOD) for the monolithic column are

within $\pm 1.4 \mu \mathrm{g} \mathrm{L}^{-1}$ at 220 and $244 \mathrm{~nm}$; and $\pm 5.2 \mu \mathrm{g} \mathrm{L}^{-1}$ at $230 \mathrm{~nm}$ when directly

compared with the packed column). The great advantage of the monolithic column

over the packed column is the decrease in operating pressure and the reduction in

retention time for each analyte, resulting in a significantly reduced analysis time; i.e.,

$2.0 \mathrm{~mL} \mathrm{~min}^{-1}$ for the packed column at an operating pressure of $3500 \mathrm{psi}$ and analysis

time of 7 minutes per sample compared to $2.0 \mathrm{~mL} \mathrm{~min}^{-1}$ for the monolithic column at

Comment [N12]: Maybe yo need to get rid of the statement about all subsequent experiments being carried out at $2 \mathrm{mLmin}^{-1}$ in the effect of mobile flow rate.

an operating pressure of $500 \mathrm{psi}$ and analysis time under 3 minutes per sample; or 3.0

$\mathrm{mL} \min ^{-1}$ and $600 \mathrm{psi}$ and analysis time under 2 minutes per sample.

\section{Application to natural samples}

To test the effect of dissolved organic matter (as DOC) on the analytical performance Double, Don't adjust space between Latin and Asian text

Formatted: Line spacing: Double

of the described direct injection HPLC method, a series of natural water samples with various DOC concentrations were collected throughout Victoria, Australia (see Table 4). Samples were collected using a $1 \mathrm{~L}$ grab glass bottles (pre-cleaned with Pyroneg, Johnson Diversey Australia, and triple rinsed with MilliQ water). All samples were stored at $4{ }^{\circ} \mathrm{C}$ and allowed to equilibrate at room temperature $\left(c a .22^{\circ} \mathrm{C}\right)$ prior to analysis.

\section{Deleted: 3}

Comment [N13]: Details need to be in methods - with city!)

Comment [DB14]: I think it is fine here, it flows on nicely with the application of natural samples - if it gets moved up at the front it may be a little disjointed in terms of flow....this is the similar flow we took for the fia paper last year

Formatted: Right: $18 \mathrm{pt}$ 
Table 4: Summary of characteristics of natural water samples analysed by direct injection HPLC.

\begin{tabular}{|c|c|c|c|c|}
\hline$\frac{\text { Sample ID }}{\text { tag }}$ & Water source & $\frac{\mathrm{DOC}^{\dagger}}{\left(\mathrm{mg} \mathrm{L}^{-1}\right)}$ & Location in Victoria & Primary land activity \\
\hline 1 & Ground water & 3.1 & South East & Cattle farm \\
\hline$\overline{2}$ & Creek (seasonal) & $\overline{4.5}$ & South East & Livestock \\
\hline$\underline{3}$ & river (metropolitan) & 6.5 & Central & Metropolitan \\
\hline$\underline{4}$ & Drinking water catchment & 10.7 & South West & Agriculture \\
\hline$\underline{5}$ & Drinking water catchment* & 11.1 & East & Natural reserve \\
\hline$\underline{6}$ & Drinking water catchment & 11.7 & South West & Agriculture \\
\hline 7 & Drinking water catchment & 10.1 & North & \\
\hline 8 & Drinking water catchment & 14.4 & North & \\
\hline
\end{tabular}

Note: *Decommissioned drinking water catchment, closed to public access.

${ }^{\dagger}$ Dissolved organic carbon (DOC) measured using a total organic carbon analyser.

The natural waters spiked with increasing amounts of atrazine, simazine and hexazinone were analysed using the direct injection method at a wavelength $(\lambda)$ of $230 \mathrm{~nm}$. The position of the DOC peak did not interfere with those of atrazine, simazine and hexazinone in any of the samples analysed ( $\mathrm{p}<0.05$ at $95 \%$ confidence interval). Statistical analysis of the recovery and relative standard deviation for all natural water samples showed strong correlation between spiked and measured concentrations (Table 5).
Deleted: The natural waters spiked with increasing amounts of atrazine, simazine and hexazinone were analysed using the direct injection method at a wavelength $(\lambda)$ of $230 \mathrm{~nm}$. The position of the DOC peak did not interfere with those of atrazine, simazine and hexazinone in any of the samples analysed ( $\mathrm{p}<0.05$ at $95 \%$ confidence interval). Statistical analysis of the recovery and relative standard deviation for all natural water samples showed strong correlation between spiked and measured concentrations (Table 4). 9

Formatted: Line spacing: Double 
Table 5: Direct injection HPLC analysis of atrazine, hexazinone and simazine in natural waters.

\begin{tabular}{|c|c|c|c|}
\hline \multirow{2}{*}{ Concentration $\left(\mu \mathrm{g} \mathrm{L}^{-1}\right)$} & \multicolumn{3}{|c|}{ Recovery \% (\%RsD) } \\
\hline & Atrazine & Hexazinone & Simazine \\
\hline$\underline{10.0}$ & $105(6.1)$ & $82(10.1)$ & $106(1.5)$ \\
\hline$\underline{15.0}$ & $\underline{99(1.3)}$ & $\underline{89(8.6)}$ & $=$ \\
\hline$\underline{25.0}$ & $\underline{92(0.6)}$ & $\underline{84(8.2)}$ & $\underline{95(0.7)}$ \\
\hline$\underline{40.0}$ & $\underline{82(0.8)}$ & $\underline{85(3.6)}$ & $\underline{98(1.4)}$ \\
\hline$\underline{50.0}$ & $\underline{80(0.3)}$ & $\underline{80(4.6)}$ & $=$ \\
\hline \multicolumn{4}{|l|}{ Statistical figures of merit } \\
\hline $\begin{array}{l}\text { Pearson } \\
\text { coefficient }\end{array}$ & $\underline{0.9965}$ & $\underline{0.9993}$ & $\underline{0.9966}$ \\
\hline$p$-value & $\underline{0.80}$ & $\underline{0.67}$ & $\underline{0.97}$ \\
\hline$\underline{\text { Correlation coefficient }}$ & $\underline{0.9930}$ & $\underline{0.9986}$ & $\underline{0.9933}$ \\
\hline
\end{tabular}

NOTE: Each of the 8 water samples at each of the concentrations was analysed in triplicate.

Samples directly injected into the HPLC without pre-treatment showed a distinct

DOC peak within the first 0.7 min compared with standards as shown in the example

chromatogram using $244 \mathrm{~nm}$ presented in Figure 3. The presence of DOC was

confirmed by 3D EEM fluorescence spectroscopy as shown in Figure 4, where

distinct humic and fulvic acid fluorophores were observed at 237-260/400-500 and

300-370/400-500 (excitation/emission wavelength) for all of the samples included in

Deleted: [31

this study[23]. 


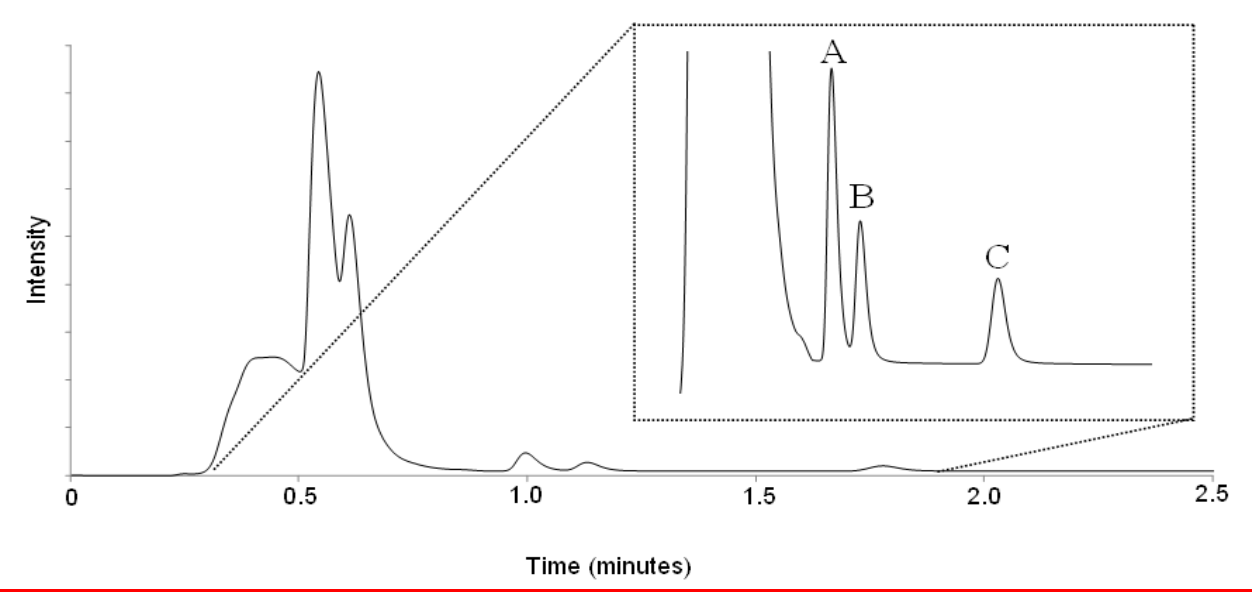

Figure 3: Effect of natural organic matter (dissolved organic matter; DOC) on monolithic chromatography performance.

NOTE: (A) hexazinone; (B) simazine; (C) atrazine. Sample number three (refer to table 2); DOC $=6.5$ $\underline{\mathrm{mg} \mathrm{L}^{-1} \text { ) spiked with } 10 \mu \mathrm{g} \mathrm{L}} \mathrm{L}^{-1}$ pesticide, $500 \mu \mathrm{L}$ injection. Mobile phase 30:70 (ACN: $\mathrm{H}_{2} \mathrm{O}$ ) with a UVvis detector $\lambda 244 \mathrm{~nm}$, flow rate $2.0 \mathrm{~mL} \mathrm{~min}^{-1}$. 


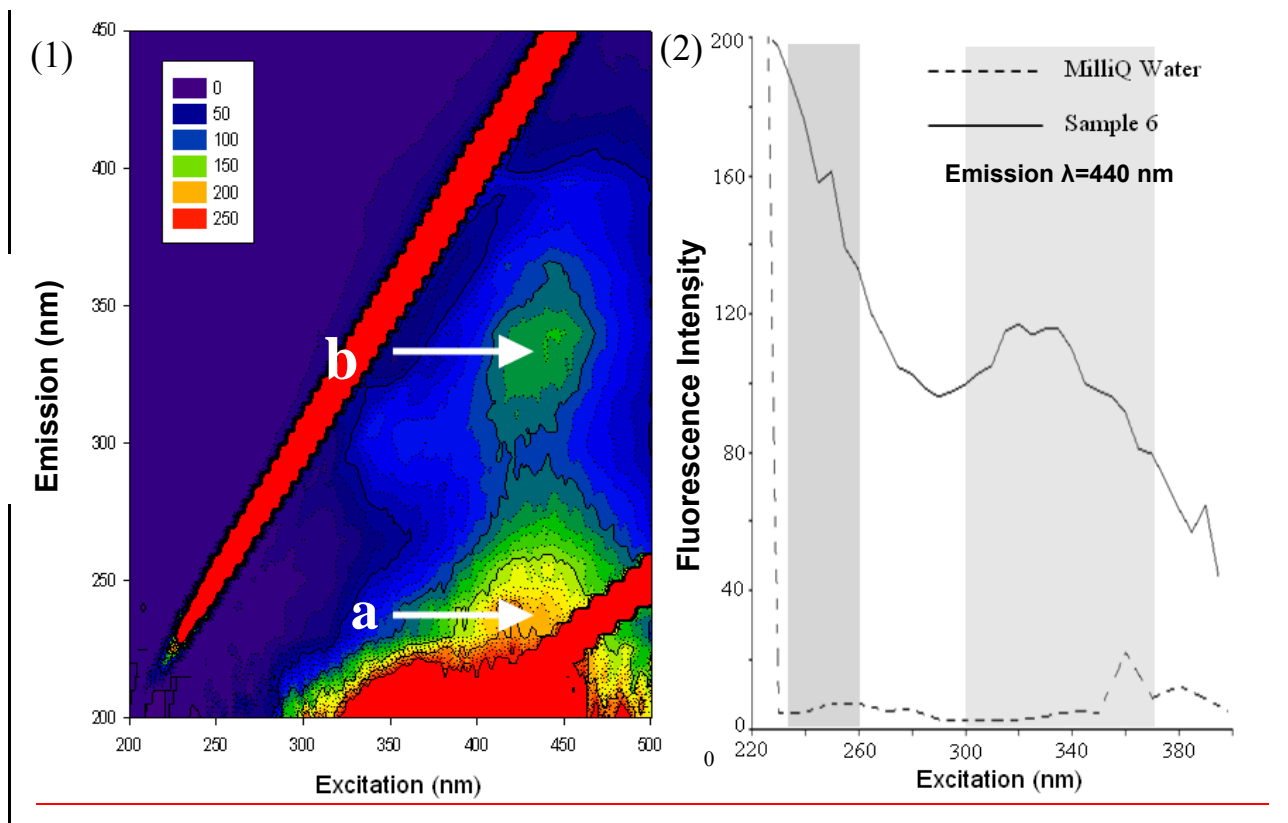

Figure 4: 3D excitation emission matrix (3D EEM) fluorescence spectroscopy in natural water for the confirmation of DOC.

Note: (1) EEM spectrum for sample number six (Table 3). Identification of two humic-like flurorphores (labelled a and b) were determined by observing distinct peaks at 237-260/400-500 and 300-370/400-500 respectively (excitation/emission wavelength)[23]; which were not present in MilliQ water standards (2) fluorescence spectrum for sample 6 at emission wavelength $\lambda=440 \mathrm{~nm}$ over the excitation ranged from 200 to $380 \mathrm{~nm}$. The spectrum indicates the presence of the humic-like fluorphores over a MilliQ blank. The observed peak at $230 \mathrm{~nm}$ in the MilliQ sample is an artefact of $\underline{\text { Raman light scatter. }}$

\section{Method validation}

Two blind comparison studies were conducted to evaluate the performance of the described multi-analyte (single wavelength; $\lambda=230 \mathrm{~nm}$ ) monolithic HPLC method utilising the natural water samples from drinking water catchment waters spiked with all three pesticides. Sample \#s 7 and 8 in Table 4 were spiked at SGS and presented to our laboratory as unknowns. The first study consisted of samples spiked with 
concentrations between 10 and $50 \mu \mathrm{g} \mathrm{L}^{-1}$ in order to assess the recovery and reproducibility of the direct injection technique described. The second study involved samples spiked with concentrations between 0.1 and $2 \mu \mathrm{g} \mathrm{L}^{-1}$ to assess and compare the analytical performance of the described HPLC method with SPE preconcentration. In this case the samples were spiked at SGS, analysed at RMIT and then sent back to SGS for reanalysis as a double blind experiment.

The analytical figures of merit for the LC-MS/MS instrument at SGS are presented below in Table 6 .

\section{Table 6: LC-MS/MS analytical figures of merit}

\begin{tabular}{|c|c|c|c|}
\hline Analyte & Atrazine & Hexazinone & Simazine \\
\hline Linear dynamic range $\left(\mu \mathrm{g} \mathrm{L}^{-1}\right)$ & $\underline{0.1-10}$ & $\underline{0.5-10}$ & $2-10$ \\
\hline Retention time (minutes) & $\underline{11.17}$ & $\underline{10.56}$ & $\underline{10.62}$ \\
\hline$\underline{\operatorname{LOD}^{a}\left(\mu \mathrm{g} \mathrm{L}^{-1}\right)}$ & $\underline{0.05}$ & $\underline{0.5}$ & $\underline{0.1}$ \\
\hline $\operatorname{MDL}^{c}\left(\mu \mathrm{gL}^{-1}\right)$ & $\underline{0.1}$ & $\underline{2.0}$ & $\underline{0.5}$ \\
\hline
\end{tabular}

The first set of spiked samples provided by SGS was analysed by direct injection HPLC after filtration. Apart from a significant difference in analysis time i.e., 12 minutes per sample by LC-MS/MS compared with $<2$ minutes by direct injection HPLC, good correlation between the spiked and measured concentrations was observed as shown in Figure 5; all of the samples were within 90\% confidence intervals for all three analytes. 


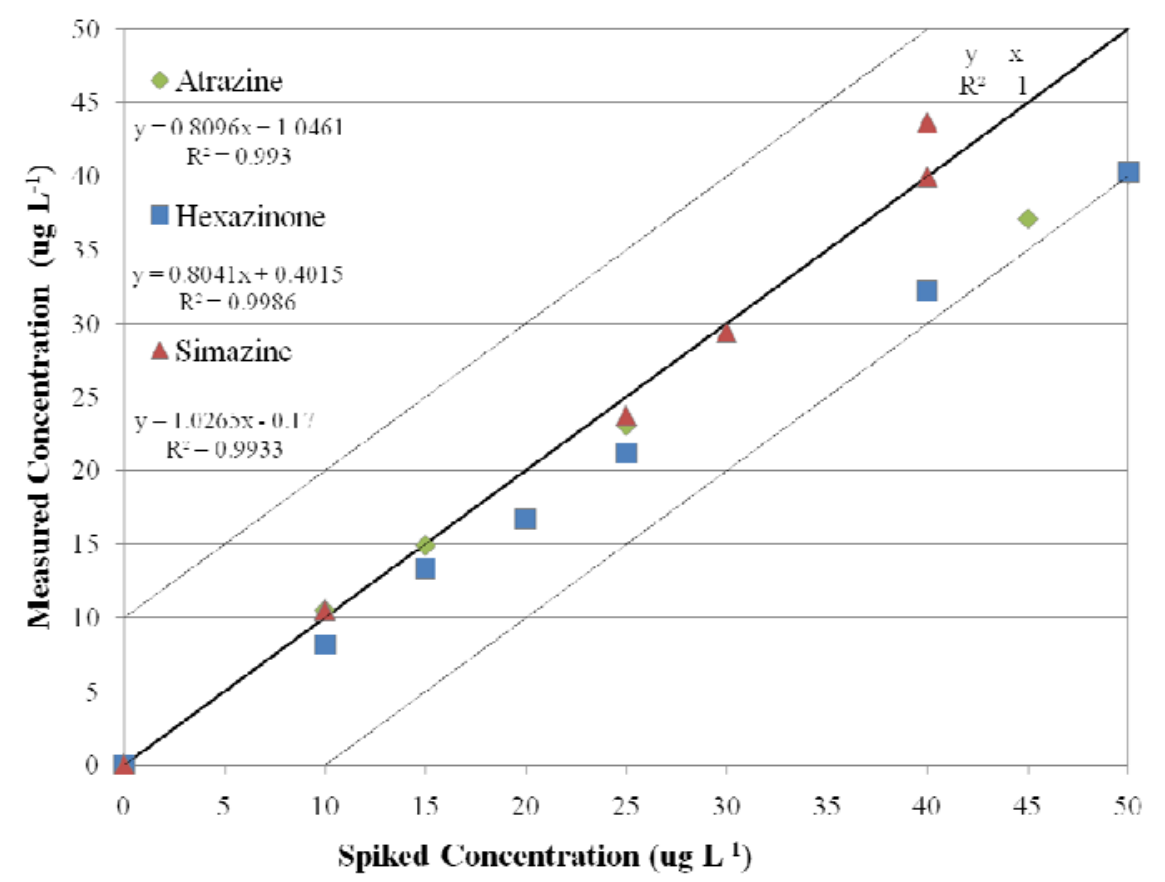

Figure 5: Blind analysis of spiked natural water samples $\left(10-50 \mu \mathrm{g} \mathrm{L}^{-1}\right)$ provided by SGS (Victoria, Australia).

When using the direct injection method the concentrations of the second set of samples were below the LOD and MDL limits presented in Table 3 . Therefore, prior to analysis, pre-concentration (by a factor of 25) of the samples was performed by solid phase extraction. The HPLC instrumentation used was not altered for the analysis of SPE extracts, i.e., the $500 \mu \mathrm{L}$ injection loop and volume was utilised.

Natural samples pre-concentrated with SPE still showed the presence of DOC within sample extracts, however a $80 \%$ reduction in the DOC peak was observed. Although SPE should eliminate the majority of DOC in extracted samples, there is a possibility that during pre-concentration some DOC is retained on and later eluted from the SPE cartridge. This finding is similar to that by Simpson [24], who found that a fraction of DOC can be retained and eluted from the SPE cartridge when performing sample extractions with a sample matrix containing DOC. The degree of retention is 
dependent upon a combination of the SPE material, the sample matrix and chemical characteristics of the DOC, and is relatively independent of concentration.

Linear regression was performed on the results obtained from the two systems. The regression between HPLC and LC-MS/MS systems showed a strong relationship between the instruments for all three herbicides as shown in Table 7. This suggests that the HPLC method compared well against the NATA accredited method and has the sensitivity required for triazine and triazinone detection. The reduced recovery observed for hexazinone is probably due to losses during extraction.

Table 7: Statistical figures of merit from analysis of spiked natural water samples $\left(0.1-2 \mu g L^{-1}\right)$ provided by SGS (Victoria, Australia).

\begin{tabular}{lccc}
\hline \multicolumn{1}{c}{ Statistical figures of merit } & $\underline{\text { Atrazine }}$ & $\underline{\text { Hexazinone }}$ & $\underline{\text { Simazine }}$ \\
\hline$\underline{\text { Slope }}$ & $\underline{0.8903}$ & $\underline{0.5278}$ & $\underline{0.9097}$ \\
\hline Pearson correlation Coefficient & $\underline{0.9824}$ & $\underline{0.9582}$ & $\underline{0.9512}$ \\
$\underline{\underline{p-v a l u e}}$ & $\underline{0.92}$ & $\underline{0.33}$ & $\underline{0.92}$ \\
Recovery \% (\%RsD) & $\underline{\underline{52(0.1)}}$ & $\underline{91(6.9)}$ \\
\hline
\end{tabular}

\section{Interferences}

The interference of 'like' compounds, in terms of peak resolution and retention time, was investigated utilising known atrazine metabolites, as well as other known triazine pesticide standards. Figure 6 illustrates the co-elution of peaks between simazine and the metabolite 2-hydroxyatrazine (Figure 6 (i)); this was observed for both the monolithic and packed columns. The other triazines analysed did not co-elute under the described conditions. 

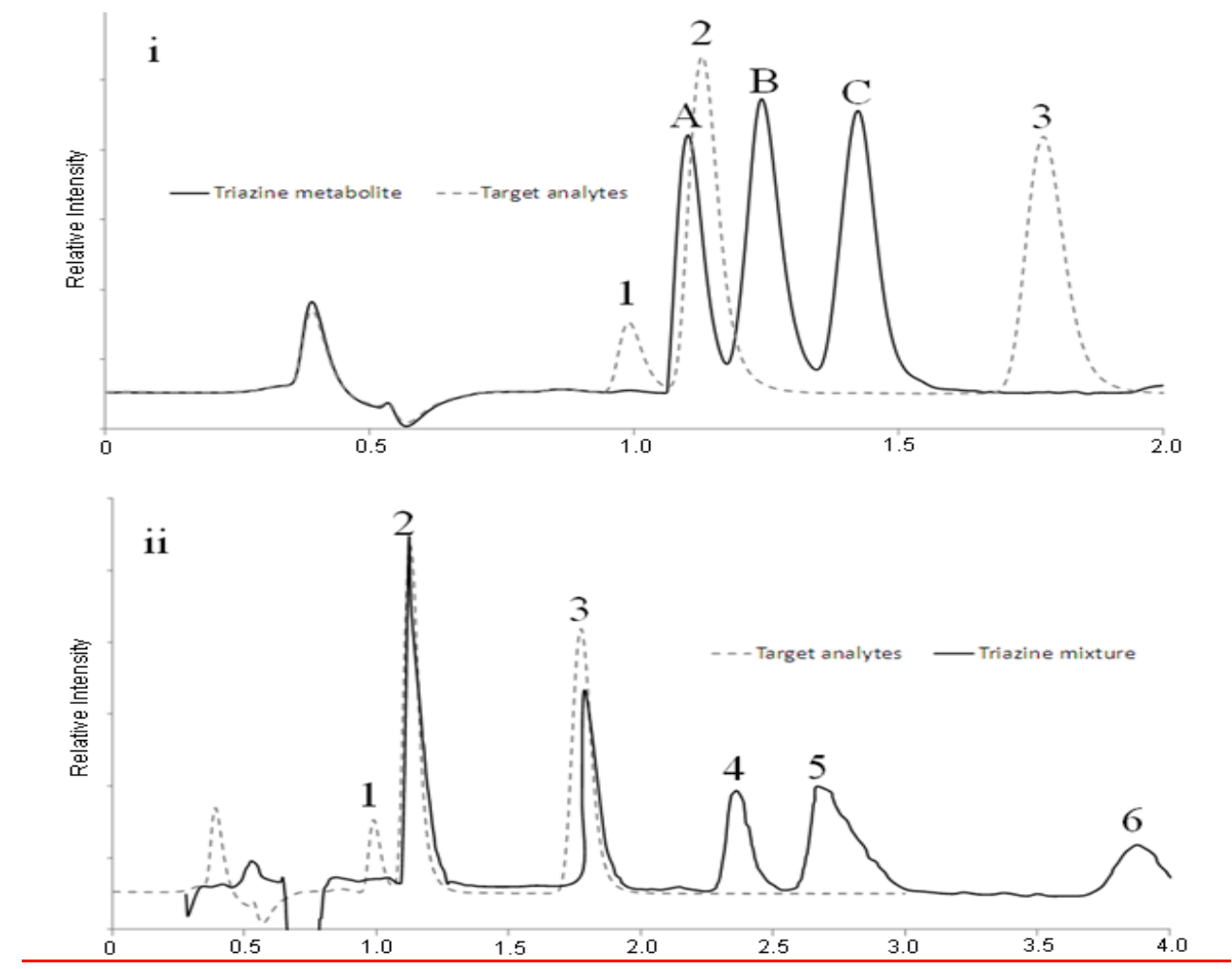

$\underline{\text { Time (minutes) }}$

Figure 6: An investigation into potential interference with other triazine pesticides and their metabolites

NOTE: Peaks identified as (A) 2-hydroxyatrazine; (B) desisopropylatrazine; (C) desethylatrazine; (1) hexazinone; (2) simazine; (3) atrazine; (4) propazine; (5) ametryn; and (6) prometryne (by injecting neat standards of each pesticide and metabolite, and comparing the retention times of each compound with a combined analyte solution). Mobile phase 30:70 (ACN: $\left.\mathrm{H}_{2} \mathrm{O}\right)$ with a UV-vis detector $(\lambda 220 \mathrm{~nm})$, flow rate $3.0 \mathrm{~mL} \mathrm{~min}{ }^{-1}$. Chromatogram (i) triazine metabolites overlaid with hexazinone, simazine and atrazine standard chromatogram as a point of reference $\left(500 \mu \mathrm{L}\right.$ injection; $100 \mu \mathrm{g} \mathrm{L} \mathrm{L}^{-1}$ metabolite stock solution); (ii) triazine mixture (total of five pesticides) overlayed with chromatogram of target analytes a point of reference $\left(500 \mu \mathrm{L}\right.$ injection; $100 \mu \mathrm{g} \mathrm{L}{ }^{-1}$ pesticide stock solution). Triazine chromatogram digitised from a paper chromatogram by "GraphClick" (Mac OS X, Arizona Software, Switzerland).

Comment [N15]: Should be in methods

Mmm maybe, but I think it is okay here, it relates only to this graph... have made an addition in the methods

Formatted: Right: $18 \mathrm{pt}$ 


\section{Conclusion}

The analytical performance of two HPLC columns (a conventional packed column

and monolithic column) with UV-vis detection at multiple wavelengths were

established and compared. It was observed that both columns were able to separate

the tested analytes well with sufficient resolution and peak asymmetry, but they

differed significantly in analysis time and operating pressure. It was found that the

$\underline{\text { monolithic column was superior in terms of reduced analyte retention times and lower }}$

operating backpressure, while limits of detection were slightly better using the packed

column. The variation in detector wavelength from 220,230 and $244 \mathrm{~nm}$ was also

investigated; it was found that $230 \mathrm{~nm}$ was the ideal wavelength for concurrent

detection of all three target analytes.

Atrazine, simazine and hexazinone in MilliQ water were concurrently detected in

under 3 minutes per sample using large volume direct injection HPLC with limits of

detection of 5.7, 4.7 and $4.0 \mu \mathrm{g} \mathrm{L}^{-1}$, respectively, without pre-concentration (validated

using LC-MS). The advantage of the described system over more traditional methods

and methods described within the literature are two fold: firstly, large volume direct

injection of the sample coupled with the monolithic column enables the time for

analysis of each sample to be significantly reduced,(eliminating the need and time for

$\underline{\text { SPE, along with subsequent affect of limiting operating pressures and flow rates }}$

associated with packed columns); secondly, the use of a low cost detector (in relation

to more sophisticated detectors; i.e., MS) using a single wavelength enables the cost

of the total analysis to be lower, enabling more samples to be analysed.

Cross validation of samples analysed by LC-MS/MS indicated good correlation with

samples spiked in the 10 to $50 \mu \mathrm{g} \mathrm{L}{ }^{-1}$ range, with correlation coefficients of better

than 0.9965 , supported by statistical analysis. Samples spiked at relatively low
Formatted: Line spacing:

Double, Don't adjust space

between Latin and Asian text

Deleted: Atrazine, simazine and

hexazinone in MilliQ water were

concurrently detected in under 3

minutes per sample using large

volume direct injection HPLC

with limits of detection of 5.5, 4.4

and $3.8 \mu \mathrm{g} \mathrm{L}^{-1}$, respectively,

without pre-concentration.

Validation of the method was

performed by an inter laboratory

comparison with a NATA

accredited LC-MS/MS method

using spiked natural water

samples. 9

Formatted: Font: 12 pt, Not Highlight

Formatted: Line spacing:

Double

Formatted: Font: $12 \mathrm{pt}$, Not Highlight

Formatted: Font: $12 \mathrm{pt}$, Not Highlight

Comment [N16]: ???

increase run times, faster flow rates etc.

Formatted: Font: $12 \mathrm{pt}$, Not Highlight

Formatted: Font: 12 pt, Not Highlight

Formatted: Font: 12 pt, Not Highlight

Formatted: Font: $12 \mathrm{pt}$, Not Highlight

Formatted: Font: 12 pt, Not Highlight

Formatted: Font: 12 pt, Not Highlight

Formatted: Right: $18 \mathrm{pt}$ 
concentrations of 0.1 to $2.0 \mu \mathrm{g} \mathrm{L}{ }^{-1}$ required preconcentration by SPE. Linear regression of the results from the two systems in the double blind experiment correlated well but recoveries were poorer in the lower concentration range, particularly for hexazinone from which we only recovered $52 \%{ }_{2}$ suggesting some losses during SPE. Recoveries of 96 and $91 \%$ were obtained for atrazine and simazine respectively in the lower concentration range.

Analysis of natural waters showed that various concentrations of DOC from 3.1 to

$11.7 \mathrm{mg} \mathrm{L}^{-1}$ had no significant affect on the resolution or separation capacity of the described HPLC method. However, while there is some potential for 'like' compounds to co-elute as shown in the case of 2-hydroxyatrazine, the method developed provides a fast, simple, cheap alternative to LC-MS/MS for multi-analyte detection of triazines with similar detection limits, and as such would be an excellent Formatted: Font: $12 \mathrm{pt}$, Not Highlight inexpensive screening method.

\section{Acknowledgments}

This research was funded by Water Quality Research Australia (formally the CRC for Water Quality and Technology) and Melbourne Water. The authors wish to extend their appreciation to Dr R. Considine and Dr N. Crosbie (Melbourne Water) for guidance, financial support and providing samples. The authors also wish to acknowledge and thank Mr A. Pellegrini and Ms A. Stenta (SGS Australia) for the analysis of water samples by LC MS/MS and assisting with the blind study.

\section{References}

[1] D.J J Hamilton, A. Ambrus, R.M. Dieterle, A.S. Felsot, C.A. Harris, P.T. Holland,

A. Katayama, N. Kurihara, J. Linders, J. Unsworth, S.S. Wong, Pure and Applied

Chemistry, 75 (2003) 1123-1155.

Formatted: Line spacing: Double, Don't adjust space between Latin and Asian text

Formatted: Line spacing: Double

Deleted: and

Formatted: Line spacing:

Double, Don't adjust space between Latin and Asian text

Deleted: ]. Akermann, F., (2007). 'The economics of atrazine'. International Journal of

Occupational and environmental Health. 13.9

[2]. Fishel, F., (2006). 'Pesticides and the environment', in

Agriculture MU Guide, University of Missouri. ब

[3]. LeBaron, H.M., McFarland,

Deleted: E., Burnside, O.C., Homer, M.L., Janis, E.M., \& Orvin, C.B., (2008). The triazine herbicides: A milestone in the development of weed control technology, in The triazine herbicides. Elsevier: San Diego. p. 1-12.

Formatted: Line spacing: Double

Formatted: Right: $18 \mathrm{pt}$ 
[2] National Health \& Medical Rresearch Council, in: the Australian Drinking Water

Guidelines, 2004.

[3] M.J. Benotti, R.A. Trenholm, B.J. Vanderford, J.C. Holady, B.D. Stanford, S.A.

Snyder, Environmental Science \& Technology, In Press (2009).

[4] US EPA, in: Drinking water contaminants list, (US EPA (Ed.), 2009*

[5] A. JunkerBuchheit, M. Witzenbacher, Journal of Chromatography A, 737 (1996)

$67-74$.

[6] Q.X. Zhou, L. Pang, G.H. Xie, J.P. Xiao, H.H. Bai, Analytical Sciences, 25 (2009)

73-76.

57] Q.X. Zhou, G.H. Xie, L. Pang, Chinese Chemical Letters, 19 (2008) 89-91.

[8] M. Mezcua, A. Agüera, J.L. Lliberia, M.A. Cortés, B. Bagó, A.R. Fernández-

Alba, Journal of Chromatography A, 1109 (2006) 222-227.

[9] G. Gervais, S. Brosillon, A. Laplanche, C. Helen, Journal of Chromatography A,

$1202(2008) 163-172$.

[10] B.L. Perkins, R.J. Bushway, L.E. Katz, Journal of AOAC, 82 (1999).

[11] L. Diaz, J. Llorca-Porcel, I. Valor, Analytica Chimica Acta, 624 (2008) 90-96.

[12] U. Ochsenbein, M. Zeh, J.-D. Berset, Chemosphere, 72 (2008) 974-980.

[13] T. Ikegami, N. Tanaka, Current Opinion in Chemical Biology, 8 (2004) 527-533.

[14] Merk, The Chromotography manual, 2009.

[15] M. Kuster, M.L.d. Alda, D. Barceló, Mass Spectrometry Reviews, 25 (2006)

$\underline{900-916 .}$

[16] P. Chocholous, D. Satínský, R. Sladkovský, M. Pospísilová, P. Solich, Talanta, $77(2008) 566-570$.

[17] A. Asperger, J.Efer, T. Koal, W. Engewald, Journal of Chromatography A, 960 (2002) 109-119.
Deleted: [4]. Kingsbury, J.A., Delzer, D.C., \& Hopple, J.A.,(2008). Anthropogenic organic compounds in source water of nine community water systems that withdraw from streams, 2002-05, in National

Water-Quality Assessment

(NAWQA) Program, USGS,

Editor. USA Department of

Interior.

[5]. Meakins, N.C., Bubb, J.M., \&

Lester, J.N., (1994). 'The

behaviour of the s-triazine

herbicides, atrazine and simazine,

during primary and secondary

biological waste water treatment'.

Chemosphere. 28(9): p. 1611-

1622. ๆ

[6]. Radcliff, G.W., (2002).

Pesticide use in australia.

Chichester: J Wiley and Sons.

[7]. Tilbury, A., (1999).

Bioremediation of atrazi ... [43]

Deleted: ). Pesticides in pools

far above safe limit, in The

Australian newspaper. May 18th

Deleted: [10]. National Health and Medical Research Council (NH\&MRC), (2004). Australian

drinking water guidelines,

Australian Government, I ... [44]

Deleted: ). Rivers pushing herbicides out to sea, in ABC News. February 23rd

Deleted: [12]. Lewis, S.E., Brodie, J.E., Bainbridge, Z.T. Rohde, K.W., Davis, A.M., Masters, B.L., Maughan, M. Devlin, M.J., Mueller, J.F ... [45]

Deleted: , Linders, J

Unsworth, J., \& Wong, S.S., (2003). 'Regulatory limits for pesticide residues in water (iupac technical report)'.

Deleted: ]. Benotti, M.J.,

Trenholm, R.A., Vanderford, B.J., Holady, J.C., Stanford, B.D., \&

Snyder, S.A., (2009).

'Pharmaceuticals and enc ... [47]

Deleted: ]. US EPA, (2009).

'Drinking water contaminats: List of contaminants \& their mcls'

[cited 2010 25/2]; Available from: http://www.epa.gov/safev ... [48]

Deleted: ]. Junker-Buchheit, A. \& Witzenbacher, M., (1996). 'Pesticide monitoring of drinking water with the help of solid-phase extraction and high-perfo ... [49]

Deleted: ]. Zhou, Q.X., Pang, L., Xie, G.H., Xiao

Deleted: P., \& Bai, H.H., (2009). 'Determination of atrazine and simazine in environmental water samples by dispersive liquid-liquid microextrac ... [50]

Formatted: Right: 18 pt 
[18] M. Bedair, Z.E. Rassi, ELECTROPHORESIS, 23 (2002) 2938-2948.

[19] D.C. Harris, Qualitative Chemical Analysis, Freeman \& Company, 1997.

[20] D.J. Beale, N.A. Porter, F.A. Roddick, Talanta, 78 (2009) 342-347.

[21] I. Baranowska, H. Barchanska, E. Pacak, Environmental Pollution, 143 (2006)

206-211.

[22] Q.X. Zhou, J.P. Xiao, W.D. Wang, G,G. Liu, Q.Z. Shi, JH. Wang, Talanta, 68 (2006) 1309-1315.

[23] N. Hudson, A. Baker, D. Reynolds, River Research and Applications, 23 (2007) 631-649.

$\left[24 \_N_{\checkmark} J \underline{K}\right.$. Simpson, Solid-phase extraction: principles, techniques and applications, CRC Press, , Harbor City, California, USA, 2000.
Deleted: ]. Zhou, Q.X., Xie,

G.H., \& Pang, L., (2008). 'Rapid determination of atrazine in

environmental water samples by a novel liquid phase

microextraction'. Chinese Chemical Letters. 19(1): p. 89-91.

Deleted: [19]. Mezcua, M., Agüera, A., Lliberia, J.L., Cortés, M.A., Bagó, B., \& FernándezAlba, A.R., (2006). 'Application of ultra performance liquid chromatography-tandem mass spectrometry to the analysis of priority pesticides in groundwater'. Journal of

Chromatography A. 1109(2): p. 222-227.

[20]. Gervais

Deleted: , Brosillon, S. Laplanche, A., \& Helen, C. (2008). 'Ultra-pressure liquid chromatography-electrospray tandem mass spectrometry for multiresidue determination of pesticides in water'. Journal of Chromatography A. 1202(2): p. 163-172.

[21]. Perkins, B.L., Bushway, R.J., \& Katz, L.E., (1999). 'Determination of hexazinone in ground water by direct injection high-performance liguid chromatography'. Journal of AOAC. 82(6). 9 .. [51]

Deleted: , \& Valor, I., (2008). 'Ultra trace determinatior ... [52]

Deleted: ]. Ochsenbein, U., Zeh, M., \& Berset, J.-D., ... [53]

Deleted: ]. Ikegami, T. \& Tanaka, N., (2004). 'Mon ... [54]

Deleted: A., \& Roddick, F.A., (2009). 'A fast screening [... [55]

Deleted: P., Wang, W.D., Liu, G.G., Shi, Q.Z., \& Wang, ... [56]

Formatted: Font: $12 \mathrm{pt}$

Deleted: N.J.K., (2000). '

Formatted: Font: $12 \mathrm{pt}$, Not Italic

Deleted: Principles

Formatted: Font: $12 \mathrm{pt}$, Not Italic

Deleted:

Formatted: Font: $12 \mathrm{pt}$, Not Italic

Deleted: ' ed. Simpson, N.J.K

Formatted: Font: $12 \mathrm{pt}$

Deleted: : CRC Press.

Formatted ... [57]

Formatted: Line spacing: Double

Formatted: Right: $18 \mathrm{pt}$ 
Pesticides are an integral part of modern agriculture. It is estimated that at the beginning of the $21^{\text {st }}$ century pesticide use worldwide exceeded US $\$ 8$ billion per annum, while herbicides accounted for $37 \%$ of total use [1, 2]. Two classes of herbicides that have received a great deal of attention in recent times are the quaternary ammonium heterocyclic s-triazines and the triazinone based pesticides. Triazine and triazinone herbicides represent widely used selective pesticides characterized by three heterocyclic nitrogen atoms in ring structures. They are generally used to control broadleaf and grassy weeds in agricultural areas, plantations, and in public and industrial landscapes [3]. The most commonly used s-triazines are atrazine, simazine, cyanazine, prometon and propazine; metribuzin and hexazinone are commonly used triazinone pesticides.

These pesticides are relatively stable in water, extremely persistent and have been detected in ground and surface waters in Australia, the UK and the US with residual levels exceeding the World Health Organization guidelines [4-7].

Continued application of these herbicides within Australia has prompted community concern as expressed in national newspaper reports by Dayton and Denholm [8] who reported an increase in observed health effects arising from pesticide over-spraying in surrounding communities in Tasmania, Australia. Denholm [9], noted simazine in Australian swimming pools at levels above the Australian allowable daily intake limit of $20 \mu \mathrm{g} \mathrm{L}^{-1}$ [10]. Similarly, Cornish [11] reported runoff of an estimated 1.5 tonnes of atrazine from farmland into surrounding oceans near the Great Barrier Reef by floodwaters (after Lewis et al. [12]).

It is common practice for water utilities to apply a risk approach to pesticide residue monitoring in drinking water catchments, where pesticides are identified and the risk 
of contamination is calculated (i.e., solubility and mobility of pesticide being applied in conjunction with the proximity and rate of application) [13]. This information is used to inform the water utility's monitoring programme. Current Australian drinking water guidelines do not enforce a sampling program frequency (although it is recommended to sample for pesticide residues monthly), nor do they specify which pesticides are to be monitored, as no single method of analysis is suitable for all the organic compounds that may be present in water. Each compound, or perhaps group of compounds, has specific analytical requirements, so monitoring for all of them would be extremely costly, time consuming, and probably unjustified [10]. To highlight the deficiencies in current monitoring programs, Benotti et al. investigated pharmaceutical and endocrine disrupting compounds (including atrazine) in USA drinking water [14]. Their study concluded that the level of tertiary treatment currently applied by 19 water utilities resulted in atrazine and other potentially harmful chemicals passing through to finished drinking water, and in some instances at concentrations as high as $0.9 \mu \mathrm{g} \mathrm{L}^{-1}$ (note current US EPA drinking water guidelines for atrazine are set at $\left.3 \mu \mathrm{g} \mathrm{L}^{-1}[15]\right)$.

\begin{tabular}{|c|c|c|}
\hline Page 6: [2] Formatted & David Beale & 09/01/2012 22:20:00 \\
\hline \multicolumn{3}{|l|}{ Not Highlight } \\
\hline Page 6: [2] Formatted & David Beale & 09/01/2012 22:20:00 \\
\hline \multicolumn{3}{|l|}{ Not Highlight } \\
\hline Page 6: [3] Formatted & David Beale & 09/01/2012 22:20:00 \\
\hline \multicolumn{3}{|l|}{ Not Highlight } \\
\hline Page 6: [3] Formatted & David Beale & 09/01/2012 22:20:00 \\
\hline \multicolumn{3}{|l|}{ Not Highlight } \\
\hline Page 6: [4] Formatted & David Beale & 09/01/2012 22:20:00 \\
\hline \multicolumn{3}{|l|}{ Not Highlight } \\
\hline Page 6: [4] Formatted & David Beale & 09/01/2012 22:20:00 \\
\hline \multicolumn{3}{|l|}{ Not Highlight } \\
\hline Page 6: [4] Formatted & David Beale & 09/01/2012 22:20:00 \\
\hline \multicolumn{3}{|l|}{ Not Highlight } \\
\hline Page 6: [5] Formatted & David Beale & 09/01/2012 22:20:00 \\
\hline
\end{tabular}


Not Highlight

\begin{tabular}{|c|c|c|}
\hline Page 6: [5] Formatted & David Beale & 09/01/ 2012 22:20:00 \\
\hline \multicolumn{3}{|l|}{ Not Highlight } \\
\hline Page 6: [6] Formatted & David Beale & 09/01/2012 22:20:00 \\
\hline \multicolumn{3}{|c|}{ Centered, No bullets or numbering } \\
\hline Page 6: [7] Formatted & David Beale & 09/01/ 2012 22:20:00 \\
\hline \multicolumn{3}{|l|}{ Not Highlight } \\
\hline Page 6: [7] Formatted & David Beale & 09/01/ 2012 22:20:00 \\
\hline \multicolumn{3}{|l|}{ Not Highlight } \\
\hline Page 6: [7] Formatted & David Beale & $09 / 01 / 2012$ 22:20:00 \\
\hline \multicolumn{3}{|l|}{ Not Highlight } \\
\hline Page 6: [8] Formatted & David Beale & 09/ 01/ 2012 22:20:00 \\
\hline \multicolumn{3}{|l|}{ Not Highlight } \\
\hline Page 6: [8] Formatted & David Beale & 09/01/2012 22:20:00 \\
\hline \multicolumn{3}{|l|}{ Not Highlight } \\
\hline Page 6: [9] Formatted & David Beale & 09/01/ 2012 22:20:00 \\
\hline \multicolumn{3}{|l|}{ Not Highlight } \\
\hline Page 6: [9] Formatted & David Beale & 09/01/ 2012 22:20:00 \\
\hline \multicolumn{3}{|l|}{ Not Highlight } \\
\hline Page 6: [10] Formatted & David Beale & 09/01/ 2012 22:20:00 \\
\hline \multicolumn{3}{|c|}{ Font: 9 pt, Do not check spelling or grammar, Not Highlight } \\
\hline Page 6: [11] Formatted & David Beale & 09/01/ 2012 22:21:00 \\
\hline \multicolumn{3}{|c|}{ Centered, None, Space Before: 0 pt, Don't keep with next } \\
\hline Page 6: [12] Formatted & David Beale & $09 / 01 / 2012$ 22:20:00 \\
\hline Font: 9 pt, Not Bold, I & elling or gra & light \\
\hline
\end{tabular}

Font: 9 pt, Do not check spelling or grammar, Not Highlight

Page 6: [12] Formatted $\quad$ David Beale $\quad 09 / 01 / 2012$ 22:20:00

Font: 9 pt, Not Bold, Do not check spelling or grammar, Not Highlight

\begin{tabular}{cc}
\hline Page 6: [13] Formatted & David Beale \\
Font: 9 pt, Do not check spelling or grammar, Not Highlight &
\end{tabular}

\begin{tabular}{lll}
\hline Page 6: [13] Formatted & David Beale & 09/ 01/ 2012 22:20:00
\end{tabular}

Font: 9 pt, Not Bold, Do not check spelling or grammar, Not Highlight

\begin{tabular}{cc}
\hline Page 6: [13] Formatted & 09/ 01/ 2012 22:20:00 \\
Font: 9 pt, Do not check spelling or grammar, Not Highlight &
\end{tabular}
Page 6: [13] Formatted
David Beale
09/ 01/2012 22:20:00

Font: 9 pt, Not Bold, Do not check spelling or grammar, Not Highlight

\begin{tabular}{|c|c|c|}
\hline Page 6: [14] Formatted & David Beale & 09/ 01/ 2012 22:20:00 \\
\hline
\end{tabular}

Page 6: [14] Formatted $\quad$ David Beale 09/ 01/ 2012 22:20:00

Font: 9 pt, Not Bold, Do not check spelling or grammar, Not Highlight

\begin{tabular}{ccc}
\hline $\begin{array}{l}\text { Page 6: [15] Formatted } \\
\text { Font: } 9 \text { pt, Not Highlight }\end{array}$ & David Beale & 09/ 01/ 2012 22:20:00 \\
\hline Page 6: [15] Formatted & David Beale & 09/ 01/ 2012 22:20:00 \\
Font: 9 pt, Not Bold, Do not check spelling or grammar, Not Highlight
\end{tabular}


Page 6: [16] Formatted

Font: 9 pt, Do not check spelling or grammar, Not Highlight

Page 6: [16] Formatted

David Beale

09/ 01/ 2012 22:20:00

Font: 9 pt, Not Bold, Do not check spelling or grammar, Not Highlight

Page 6: [17] Comment [N1]
Are these really 2000 and 1000 ug/L?????

Page 6: [18] Comment [DB2] David Beale

08/ 05/2010 15:41:00

Page 6: [18] Comment [DB2]

Yes.. the LOD was reported as $\mathrm{ug} / \mathrm{ml}$ which is the same as $\mathrm{mg} / \mathrm{l}$ isn't it?

Page 6: [19] Formatted David Beale

$08 / 05 / 201015: 41: 00$

Font: 9 pt, Do not check spelling or grammar, Not Highlight

Page 6: [19] Formatted

David Beale

09/ 01/ 2012 22:20:00

Font: 9 pt, Not Bold, Do not check spelling or grammar, Not Highlight

Page 6: [20] Formatted

David Beale

09/ 01/ 2012 22:20:00

Font: 9 pt, Do not check spelling or grammar, Not Highlight

Page 6: [20] Formatted

David Beale

09/ 01/ 2012 22:20:00

Font: 9 pt, Not Bold, Do not check spelling or grammar, Not Highlight

Page 6: [21] Formatted

David Beale

09/01/ 2012 22:20:00

Font: 9 pt, Do not check spelling or grammar, Not Highlight

Page 6: [22] Formatted

David Beale

09/ 01/2012 22:21:00

Default Paragraph Font, Font: Arial Narrow, English (Australia), Do not check spelling or grammar

Page 6: [23] Formatted

David Beale

09/ 01/2012 22:20:00

Font: 9 pt, Not Bold, Do not check spelling or grammar, Not Highlight

Page 6: [24] Formatted

David Beale

09/ 01/2012 22:20:00

Font: 9 pt, Do not check spelling or grammar, Not Highlight

Page 6: [25] Formatted

David Beale

09/01/ 2012 22:21:00

Centered, None, Space Before: 0 pt, Don't keep with next

Page 6: [26] Formatted

David Beale

09/ 01/ 2012 22:20:00

Font: 9 pt, Not Bold, Do not check spelling or grammar, Not Highlight

Page 6: [26] Formatted

David Beale

09/01/2012 22:20:00

Font: 9 pt, Do not check spelling or grammar, Not Highlight

Page 6: [26] Formatted

David Beale

09/ 01/2012 22:20:00

Font: 9 pt, Not Bold, Do not check spelling or grammar, Not Highlight

Page 6: [27] Formatted

David Beale

09/ 01/ 2012 22:20:00

Font: 9 pt, Do not check spelling or grammar, Not Highlight

Page 6: [27] Formatted

David Beale

09/ 01/2012 22:20:00

Font: 9 pt, Not Bold, Do not check spelling or grammar, Not Highlight

Page 6: [27] Formatted

David Beale

09/01/ 2012 22:21:00

Font: 9 pt, Not Italic, Do not check spelling or grammar, Not Highlight

$\begin{array}{lll}\text { Page 6: [27] Formatted } & \text { David Beale } & \text { 09/ 01/2012 22:20:00 }\end{array}$

Font: 9 pt, Do not check spelling or grammar, Not Highlight

Page 6: [27] Formatted

David Beale

09/ 01/2012 22:20:00

Font: 9 pt, Do not check spelling or grammar

\begin{tabular}{ccc}
\hline Page 6: [28] Formatted & David Beale & 09/ 01/ 2012 22:20:00 \\
Font: 9 pt, Do not check spelling or grammar, Not Highlight & \\
\hline
\end{tabular}


Font: 9 pt, Not Bold, Do not check spelling or grammar, Not Highlight

\begin{tabular}{|c|c|c|}
\hline Page 6: [29] Formatted & David Beale & 09/01/2012 22:20:00 \\
\hline \multicolumn{3}{|c|}{ Font: $9 \mathrm{pt}$, Not Highlight } \\
\hline Page 6: [29] Formatted & David Beale & 09/01/2012 22:20:00 \\
\hline
\end{tabular}

$\begin{array}{ccc}\text { Page 6: [30] Formatted } & \text { David Beale } & \text { 09/ 01/ 2012 22:20:00 } \\ \text { Font: } 9 \text { pt, Do not check spelling or grammar, Not Highlight } & \end{array}$

Page 6: [30] Formatted David Beale 09/ 01/ 2012 22:20:00

Font: 9 pt, Not Bold, Do not check spelling or grammar, Not Highlight

\begin{tabular}{ll}
\hline Page 6: [31] Formatted & David Beale \\
Font: 9 pt, Do not check spelling or grammar, Not Highlight &
\end{tabular}

Page 6: [31] Formatted David Beale 09/ 01/ 2012 22:20:00

Font: 9 pt, Not Bold, Do not check spelling or grammar, Not Highlight

Page 6: [32] Formatted David Beale 09/ 01/2012 22:21:00

Font: 9 pt, Not Italic, Do not check spelling or grammar, Not Highlight

\begin{tabular}{ll}
\hline Page 6: [32] Formatted David Beale & 09/ 01/ 2012 22:20:00 \\
Font: 9 pt, Do not check spelling or grammar, Not Highlight &
\end{tabular}

Page 6: [32] Formatted David Beale 09/ 01/ 2012 22:20:00

Font: 9 pt, Not Bold, Do not check spelling or grammar, Not Highlight

Page 6: [33] Formatted David Beale 09/ 01/ 2012 22:20:00

Font: 9 pt, Do not check spelling or grammar, Not Highlight

Page 6: [33] Formatted David Beale 09/ 01/ 2012 22:20:00

Font: 9 pt, Not Bold, Do not check spelling or grammar, Not Highlight

\begin{tabular}{ll}
\hline Page 6: [34] Formatted & David Beale \\
Font: 9 pt, Do not check spelling or grammar, Not Highlight & \\
\hline
\end{tabular}

Page 6: [34] Formatted David Beale 09/ 01/ 2012 22:20:00

Font: 9 pt, Not Bold, Do not check spelling or grammar, Not Highlight

Page 6: [35] Formatted David Beale 09/ 01/ 2012 22:20:00

Font: 9 pt, Do not check spelling or grammar, Not Highlight

\begin{tabular}{ccc}
\hline Page 6: [36] Formatted & David Beale & 09/ 01/ 2012 22:21:00 \\
Centered, None, Space Before: & 0 pt, Don't keep with next & \\
\hline Page 6: [37] Formatted & David Beale & 09/ 01/ 2012 22:20:00
\end{tabular}

Font: 9 pt, Not Bold, Do not check spelling or grammar, Not Highlight

\begin{tabular}{ccc}
\hline Page 6: [38] Formatted & David Beale & 09/ 01/ 2012 22:20:00 \\
Font: 9 pt, Do not check spelling or grammar, Not Highlight &
\end{tabular}

Page 6: [38] Formatted David Beale 09/ 01/ 2012 22:20:00

Font: 9 pt, Not Bold, Do not check spelling or grammar, Not Highlight

Page 6: [38] Formatted David Beale 09/ 01/ 2012 22:20:00

Font: 9 pt, Do not check spelling or grammar, Not Highlight

Page 6: [38] Formatted David Beale 09/ 01/ 2012 22:20:00

Font: 9 pt, Not Bold, Do not check spelling or grammar, Not Highlight

\begin{tabular}{ccc}
\hline Page 6: [38] Formatted & David Beale & 09/ 01/2012 22:20:00 \\
Font: 9 pt, Do not check spelling or grammar, Not Highlight & \\
\hline
\end{tabular}

Page 6: [38] Formatted David Beale $\quad$ 09/ 01/ 2012 22:20:00
Font: 9 pt, Not Bold, Do not check spelling or grammar, Not Highlight


Page 6: [38] Formatted

David Beale

09/ 01/ 2012 22:20:00

Font: 9 pt, Do not check spelling or grammar, Not Highlight

Page 6: [38] Formatted

David Beale

09/ 01/ 2012 22:20:00

Font: 9 pt, Not Bold, Do not check spelling or grammar, Not Highlight

Page 6: [38] Formatted

David Beale

09/ 01/2012 22:20:00

Font: 9 pt, Not Highlight

$\begin{array}{lll}\text { Page 6: [38] Formatted } & \text { David Beale } & \text { 09/ 2012 22:20:00 }\end{array}$

Font: $9 \mathrm{pt}$, Do not check spelling or grammar

$\begin{array}{lll}\text { Page 6: [39] Formatted } & \text { David Beale } & \text { 09/ 01/ 2012 22:20:00 }\end{array}$

Font: 9 pt, Do not check spelling or grammar, Not Highlight

Page 6: [39] Formatted $\quad$ David Beale $\quad$ 09/ 01/ 2012 22:20:00

Font: 9 pt, Not Bold, Do not check spelling or grammar, Not Highlight

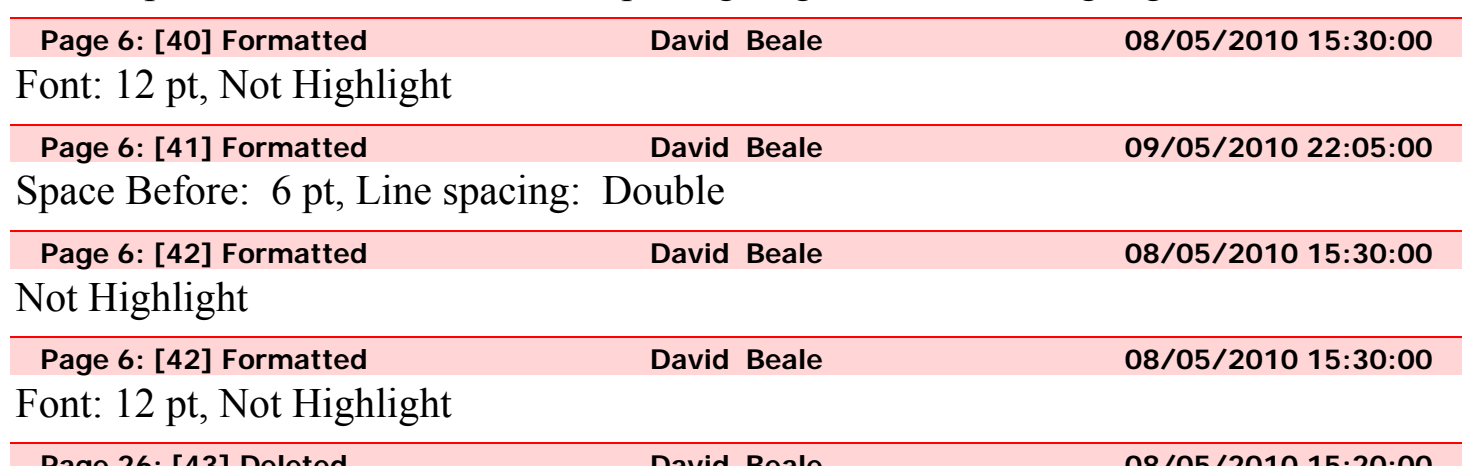

[4]. Kingsbury, J.A., Delzer, D.C., \& Hopple, J.A.,(2008). Anthropogenic organic

compounds in source water of nine community water systems that withdraw from streams, 2002-05, in National Water-Quality Assessment (NAWQA) Program, USGS, Editor. USA Department of Interior.

[5]. Meakins, N.C., Bubb, J.M., \& Lester, J.N., (1994). 'The behaviour of the striazine herbicides, atrazine and simazine, during primary and secondary biological waste water treatment'. Chemosphere. 28(9): p. 1611-1622.

[6]. Radcliff, G.W., (2002). Pesticide use in australia. Chichester: J Wiley and Sons.

[7]. Tilbury, A., (1999). 'Bioremediation of atrazine-contaminated groundwater'.

Journal of Australina Water and Wastewater Association. 26(6): p. 27-29.

[8]. Dayton, L. \& Denholm, M. (2009). When farm sprays go astray, in The

Australian newspaper. April 11th

[9]. Denholm, M. ( 
[10]. National Health and Medical Research Council (NH\&MRC), (2004). Australian drinking water guidelines, Australian Government, Editor.

[11]. Cornish, M.

Page 26: [45] Deleted David Beale

08/ 05/ 2010 15:20:00

[12]. Lewis, S.E., Brodie, J.E., Bainbridge, Z.T., Rohde, K.W., Davis, A.M., Masters,

B.L., Maughan, M., Devlin, M.J., Mueller, J.F., \& Schaffelke, B., (2009). 'Herbicides:

A new threat to the great barrier reef'. Environmental Pollution. 157(8-9): p. 24702484.

[13]. Hamilton, D.J., Ambrus, A., Dieterle, R.M., Felsot, A.S., Harris, C.A., Holland, P.T., Katayama, A., Kurihara

Page 26: [46] Deleted David Beale 08/ 05/ 2010 15:20:00

, Linders, J., Unsworth, J., \& Wong, S.S., (2003). 'Regulatory limits for pesticide residues in water - (iupac technical report)'. Pure and Applied Chemistry. 75(8): p. 1123-1155.

Page 26: [47] Deleted David Beale 08/ 05/ 2010 15:20:00

]. Benotti, M.J., Trenholm, R.A., Vanderford, B.J., Holady, J.C., Stanford, B.D., \&

Snyder, S.A., (2009). 'Pharmaceuticals and endocrine disrupting compounds in u.S. Drinking water'. Environmental Science \& Technology. In Press. water with the help of solid-phase extraction and high-performance liquid chromatography'. Journal of Chromatography A. 737(1): p. 67-74.
} 
P., \& Bai, H.H., (2009). 'Determination of atrazine and simazine in environmental water samples by dispersive liquid-liquid microextraction with high performance liquid chromatography'. Analytical Sciences. 25(1): p. 73-76.

, Brosillon, S., Laplanche, A., \& Helen, C., (2008). 'Ultra-pressure liquid

chromatography-electrospray tandem mass spectrometry for multiresidue determination of pesticides in water'. Journal of Chromatography A. 1202(2): p. 163 172.

[21]. Perkins, B.L., Bushway, R.J., \& Katz, L.E., (1999). 'Determination of hexazinone in ground water by direct injection high-performance liguid chromatography'. Journal of AOAC. 82(6).

[22]. Diaz, L., Llorca-Porcel

, \& Valor, I., (2008). 'Ultra trace determination of 31 pesticides in water samples by

direct injection-rapid resolution liquid chromatography-electrospray tandem mass spectrometry'. Analytica Chimica Acta. 624(1): p. 90-96.

Page 27: [53] Deleted

David Beale

08/ 05/ $201015: 20: 00$

]. Ochsenbein, U., Zeh, M., \& Berset, J.-D., (2008). 'Comparing solid phase

extraction and direct injection for the analysis of ultra-trace levels of relevant explosives in lake water and tributaries using liquid chromatography-electrospray tandem mass spectrometry'. Chemosphere. 72(6): p. 974-980.

Page 27: [54] Deleted 
[26]. Chocholous, P., Satínský, D., Sladkovský, R., Pospísilová, M., \& Solich, P., (2008). 'Determination of pesticides fenoxycarb and permethrin by sequential injection chromatography using miniaturized monolithic column'. Talanta. 77(2): p. $566-570$.

[27]. Harris, D.C., (1997). 'Qualitative chemical analysis'.Freeman \& Company. [28]. Beale, D.J., Porter,

Page 27: [55] Deleted

David Beale

08/ 05/ 2010 15:20:00

A., \& Roddick, F.A., (2009). 'A fast screening method for the presence of atrazine

and other triazines in water using flow injection with chemiluminescent detection'.

Talanta. 78(2): p. 342-347.

[29]. Baranowska, I., Barchanska, H., \& Pacak, E., (2006). 'Procedures of trophic chain samples preparation for determination of triazines by hplc and metals by icpaes methods'. Environmental Pollution. 143(2): p. 206-211.

[30]. Zhou, Q.X., Xiao,

Page 27: [56] Deleted David Beale 08/ 05/2010 15:20:00

P., Wang, W.D., Liu, G.G., Shi, Q.Z., \& Wang, J.H., (2006). 'Determination of atrazine and simazine in environmental water samples using multiwalled carbon nanotubes as the adsorbents for preconcentration prior to high performance liquid chromatography with diode array detector'. Talanta. 68(4): p. 1309-1315.

[31]. Hudson, N., Baker, A., \& Reynolds, D., (2007). 'Fluorescence analysis of dissolved oganic matter in natural, waste and polluted waters- a review'. River Research and Applications. 23: p. 631-649.

[32]. 